\title{
Collaborative decision-analytic framework to maximize resilience of tidal marshes to climate change
}

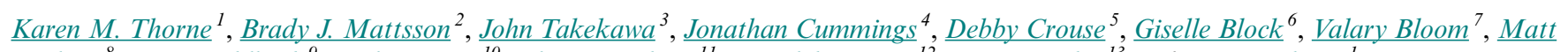
Gerhart $^{8}, \underline{\text { Steve Goldbeck }}^{9}$, Beth Huning $^{10}$, Christina Sloop $^{11}, \underline{\text { Mendel Stewart }}^{12}, \underline{\text { Karen Tavlor }}^{13} \frac{\text { and Laura Valoppi }}{}^{1}$

\begin{abstract}
Decision makers that are responsible for stewardship of natural resources face many challenges, which are complicated by uncertainty about impacts from climate change, expanding human development, and intensifying land uses. A systematic process for evaluating the social and ecological risks, trade-offs, and cobenefits associated with future changes is critical to maximize resilience and conserve ecosystem services. This is particularly true in coastal areas where human populations and landscape conversion are increasing, and where intensifying storms and sea-level rise pose unprecedented threats to coastal ecosystems. We applied collaborative decision analysis with a diverse team of stakeholders who preserve, manage, or restore tidal marshes across the San Francisco Bay estuary, California, USA, as a case study. Specifically, we followed a structured decision-making approach, and we using expert judgment developed alternative management strategies to increase the capacity and adaptability to manage tidal marsh resilience while considering uncertainties through 2050. Because sea-level rise projections are relatively confident to 2050, we focused on uncertainties regarding intensity and frequency of storms and funding. Elicitation methods allowed us to make predictions in the absence of fully compatible models and to assess short- and long-term trade-offs. Specifically we addressed two questions. (1) Can collaborative decision analysis lead to consensus among a diverse set of decision makers responsible for environmental stewardship and faced with uncertainties about climate change, funding, and stakeholder values? (2) What is an optimal strategy for the conservation of tidal marshes, and what strategy is robust to the aforementioned uncertainties? We found that when taking this approach, consensus was reached among the stakeholders about the best management strategies to maintain tidal marsh integrity. A Bayesian decision network revealed that a strategy considering sea-level rise and storms explicitly in wetland restoration planning and designs was optimal, and it was robust to uncertainties about management effectiveness and budgets. We found that strategies that avoided explicitly accounting for future climate change had the lowest expected performance based on input from the team. Our decision-analytic framework is sufficiently general to offer an adaptable template, which can be modified for use in other areas that include a diverse and engaged stakeholder group.
\end{abstract}

Key Words: Bayesian decision network; climate change; expert elicitation; San Francisco Bay; sea-level rise; structured decision making; tidal marsh

\section{INTRODUCTION}

Natural resource managers, planners, and policy makers are faced with uncertainty in managing for sustainable long-term ecosystems in the face of continued human development and climatic change (Walker et al. 2002, McGranahan et al. 2007, Nichols et al. 2011). Reconciling these uncertainties for long-term conservation and ecosystem resilience is especially challenging when working at the landscape or regional scale, where numerous jurisdictions and stakeholders are involved (Beever et al. 2014). This is particularly true in coastal zones where impacts from changes in the climate, e.g., storms and sea-level rise (SLR), threaten coastal ecosystems, which impact several stakeholder groups with differing values and are adjacent to areas with dense and growing human populations (Bernhardt and Leslie 2013). Coastal ecosystems are some of the most threatened, with human population density triple that of areas further from the coast (Small and Nicholls 2003), and the population is expected to continue to grow (Bengtsson et al. 2006). The resilience of coastal ecosystems, which is the capacity to undergo change and disturbance but retain essentially the same functions, is highly uncertain and difficult to manage (Walker et al. 2002, 2004). For conservation entities to manage resilience and adapt, they must account for uncertainties about the rate, magnitude, and likelihood of effects of climate change, particularly when management strategies have not been identified and their effectiveness is unknown (Heller and Zavaleta 2009, Nichols et al. 2011). Coastal conservation strategies that address a range of future potential scenarios are expected to be more beneficial than strategies that consider a single scenario (Veloz et al. 2013). Developing and implementing conservation strategies are often hindered by the diversity of stakeholders with competing objectives and by uncertain budgets (Wilson et al. 2007, Needles et al. 2013).

Within coastal ecosystems, tidal marshes offer an excellent case study for examining ways in which decision makers can best use limited funds for improving resilience that address both ecological and social concerns. Tidal marshes are among the most ecologically productive and economically valuable ecosystems in the world (Mitsch and Gosselink 1993, Archibold 1995, Bell 1997). They provide ecosystem services that include water regulation, coastal protection, erosion control and sediment retention, carbon sequestration, nutrient cycling, recreation, fisheries, and wildlife habitat (King and Lester 1995, Costanza et

${ }^{1}$ USGS Western Ecological Research Center, ${ }^{2}$ Department of Integrative Biology and Biodiversity Research, University of Natural Resources and Life Sciences, Vienna, Austria, ${ }^{3}$ USGS Western Ecological Research Center, San Francisco Bay Estuary Field Station, ${ }^{4}$ University of Vermont, ${ }^{5}$ USFWS, Endangered Species Recovery Program, ${ }^{6}$ USFWS, Inventory \& Monitoring, ${ }^{7}$ USFWS, Sacramento Field Office, ${ }^{8}$ State Coastal Conservancy, ${ }^{9}$ Bay Conservation and Development Commission, ${ }^{10}$ San Francisco Bay Joint Venture, ${ }^{11}$ Blue Earth Consultants, ${ }^{12}$ USFWS, Carlsbad Fish and Wildlife Office, ${ }^{13}$ California Department of Fish \& Wildlife, Napa-Sonoma Marshes Wildlife Area 
al. 1997, Lougheed et al. 2001, Zimmerman et al. 2002, Kirwan and Murray 2008, Barbier et al. 2011, Gedan et al. 2011, Greenberg 2012, Findlay and Fischer 2013). For example, it has been estimated that each hectare of tidal marsh provides $\$ 8236$ USD in coastal protection annually (Barbier et al. 2011).

Conservation of tidal marshes and the services they provide presents a great challenge in the face of climate change. They are expected to experience increased flooding from SLR and greater storm frequency and intensity, which will increase inundation and erosion (Kirwan and Murray 2007, Solomon et al. 2009). SLR projections globally range from 0.6 to as much as $1.9 \mathrm{~m}$ by 2100 (Vermeer and Rahmstorf 2009, Grinsted et al. 2010, Jevrejeva et al. 2010, 2012). Storms pose significant threats to coastal areas because of water-level surges, sustained winds, erosion, and large amounts of rainfall in a short period of time, and can vary within systems (Mousavi et al. 2011). Conserving tidal marshes under projected climate impacts is challenged by existing human infrastructure and land use, along with the diverse stakeholders and concomitant concerns regarding the suite of services that these tidal marshes provide (Convertino and Valverde 2013). An explicit decision-analytic framework that can address the challenges of managing for resilience of tidal marshes and their ecosystem services would offer much-needed assistance for decision makers struggling to allocate limited resources in the face of social-ecological complexity and uncertainties.

Our goal was to develop and evaluate an initial collaborative decision analysis (CDA) that could be further refined to identify an optimal conservation approach using expert judgment and could be implemented by a diverse set of stakeholders who manage and restore tidal marshes. After building a decision model with stakeholders' predictions and how they trade off competing objectives, we identified an optimal strategy that is robust to the focal sources of uncertainty. Specifically we had two questions: (1) Can CDA lead to consensus among a diverse set of decision makers responsible for environmental stewardship and faced with uncertainties about climate change, funding, and stakeholder values? (2) What is an optimal strategy for conservation of tidal marshes and what strategy is robust to the aforementioned uncertainties? We identified measures of success for a suite of fundamental objectives that were then linked with five alternative management strategies to reach those objectives. We used expert elicitation to predict the outcomes of these strategies, taking into account effects of SLR, storm events, and available funding. We then examined trade-offs between short- and long-term conservation of ecological integrity and endangered species, which were then analyzed using a Bayesian decision network with the aim of identifying an optimal strategy that is robust to the focal sources of uncertainty.

\section{METHODS}

\section{Study area}

San Francisco Bay (SFB) is the largest estuary on the Pacific coast of North America and an important site for migratory birds and endemic tidal marsh wildlife (Takekawa et al. 2006). In 1850, SFB tidal marshes covered an estimated $2200 \mathrm{~km}^{2}$ (Atwater et al. 1979), but fragmentation and modification through local- and watershed-scale land use changes resulted in loss of more than $80 \%$ of these marshes (Goals Project 2000). In this highly urbanized region (Nichols et al. 1986), tidal marsh wildlife were negatively affected by habitat and population fragmentation, increased predation from human-associated nuisance species, invasive species, and other threats such as pollution. Sea level rose $19.3 \mathrm{~cm}$ between 1900 and 2000 in SFB (Cayan et al. 2006), with future projections up to $1.4 \mathrm{~m}$ for California by 2100 (Cayan et al. 2009, NRC 2012). Today, SFB is an urban landscape consisting of more than 8 million people and has some of the largest urban centers in North America (Goals Project 2000). Because this urban matrix limits the ability of tidal marshes to expand or migrate inland with projected SLR (see EcoAtlas Baylands; $\underline{\text { http:// }}$ www.sfei.org/content/ecoatlas habitats), this coastal ecosystem is particularly vulnerable to climate change (Bulleri and Chapman 2010). Models of future inundation because of storm surges under alternate SLR scenarios indicate that a $50-\mathrm{cm}$ and a $150-\mathrm{cm}$ SLR would increase vulnerable areas by $20 \%\left(372 \mathrm{~km}^{2}\right)$ and $60 \%(495$ $\mathrm{km}^{2}$ ), respectively (Knowles 2010). Storm surges have been shown to cause extended flooding in the marsh (Thorne et al. 2013) that negatively affect endemic wildlife. During such flood events, tidal marshes buffer storm effects on the adjoining human communities and infrastructure (Costanza et al. 2008). Up to $93 \%$ of current SFB tidal marsh is projected to be flooded by 2100 , and landward migration of future tidal marsh habitat is heavily constrained by the lack of connectivity to suitable upland areas (Stralberg et al. 2011).

Even though tidal marshes have been known to provide important ecosystem services, they have endured more than 150 years of degradation by humans. This degradation has led to the listing of endangered and threatened species and the establishment of protected areas. Population declines and degradation of ecosystem processes and function have compromised highly valued ecosystem services including recreational activities, e.g., birding and hunting, and flood protection (Goals Project 2000). Responding to historical losses and ongoing threats to tidal marshes in SFB, a diverse group of stakeholders has been engaged to ensure tidal marsh persistence in the face of human growth and development (Goals Project 2000). Stakeholders in SFB are mostly represented by federal agencies such as the U.S. Fish and Wildlife Service (USFWS), the U.S. Geological Survey, and the Army Corp of Engineers; state agencies such as the California Department of Fish and Wildlife and California state parks; and regional agencies and groups such as East Bay Regional Parks and county land trusts. Most tidal wetlands and open space are managed and owned by these groups, with little owned by civil society in SFB. In the past two decades, extensive conservation and restoration efforts worth millions of dollars have been made to conserve and restore tidal marshes in SFB (Goals Project 2000). In 2013, USFWS finalized a recovery plan for the tidal marsh ecosystems of SFB with an estimated $\$ 1.3$ billion cost (USFWS 2013). This plan included recovery objectives over a 50 -year period for 17 species of imperiled birds, plants, and animals known to be highly susceptible to climate change effects (Takekawa et al. 2006, Thorne et al. 2012).

\section{Approach}

We applied CDA to inform conservation of tidal marshes in SFB. We defined CDA as a transparent, open, iterative process for informing conservation that includes a decision-analytic approach. Although decision analysis is an important component, a key feature of CDA that distinguishes it from other 
approaches is stakeholder engagement, team formation, and governance (Blomquist et al. 2010, Gregory et al. 2012, Conroy and Peterson 2013). Although challenges of solving multicriteria decision problems have received much attention in the conservation and natural resource management literature (Linkov and Moberg 2011), challenges of solving decision problems with multiple objectives and multiple stakeholders have received less attention. Another key feature of CDA is an iterative process to deconstructing a decision problem into logical steps and providing a clear decision structure informed by the relevant decision maker, experts, and stakeholders. Structured decision making (SDM) is a fully codified process that provides clear descriptions of steps for conducting CDA. SDM offers an approach to address problems on the basis of decision theory and risk analysis (Runge et al. 2011 a, Gregory et al. 2012, Conroy and Peterson 2013, USFWS 2014). The steps followed under a SDM framework include assessing problems, objectives, alternatives, consequences, and trade-offs (Fig. 1, PrOACT; Hammond et al. 1999).

Fig. 1. Structured decision making (SDM) is a fully codified process that provides clear descriptions of steps for conducting collaborative decision analysis (CDA). SDM offers an approach to address problems on the basis of decision theory and risk analysis. The steps followed under a SDM framework include assessing Problems, Objectives, Alternatives, Consequences, and Trade-offs (PrOACT; Hammond et al. 1999).

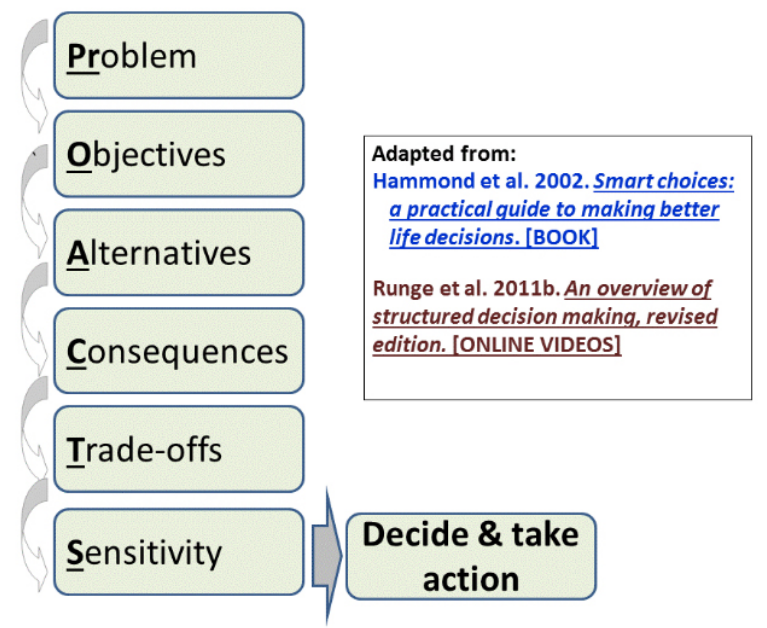

Box 1. PrOACT steps for applying structured decision making (Fig. 1) in a collaborative context

1. Problem definition and stakeholder engagement. An essential element throughout SDM in a collaborative context is team formation, which involves engagement of the relevant stakeholders and experts (henceforth partners; Gregory et al. 2012). Organizations that contribute major resources toward planning or implementation of conservation actions must be included or at least accounted for during the first and all steps of the process to ensure successful implementation of the decision. This is particularly essential during the first step, which involves defining the problem and the management context. Experts with a keen understanding of relevant system dynamics but also a sense for the application of this information to decision making should also be included. Ideally, one expert who works outside of the focal conservation area/region should be involved to provide an external perspective and to avoid "group think." A decision analyst who has experience applying quantitative decisionanalytic tools to conservation problems must also be involved. One of the partners must take the role of team coordinator to organize meetings and serve as a point of contact between the decision analyst and the partners. The coordinator helps communicate the decision context and elements to be included in the decision analysis, and how the results of the decision analysis should be applied by the decision makers. To summarize this step, partners are identified and engaged, a concise decision question is developed, relevant legal or regulatory issues are listed, and the spatial and temporal dimensions of the problem are defined. These elements form a conceptual foundation for any application of SDM in a collaborative context.

2. Objectives and drivers. Another crucial step in the process is to elicit, ideally from the decision makers, the ultimate desires of the stakeholders in conducting the conservation effort as defined in the first step. Here, we distinguish two types of objectives: fundamental and means objectives. Fundamental objectives have intrinsic importance and are the ultimate desired end points of a conservation effort. Means objectives, by contrast, are subservient to achieving these fundamental objectives. Fundamental objectives may be means objectives for other fundamental objectives, something often apparent when constructing a hierarchical diagram that shows the conceptual linkages between objectives. Eliciting objectives from participants often involves asking the following questions: What are your concerns? What would you like to ultimately achieve? What do you need to satisfy stakeholders? Often there are external drivers, i.e., those that are beyond the control of decision makers, such as climate change. There can be a large amount of uncertainty regarding the magnitude of these drivers and their effects on the objectives External drivers should be identified so that they can later be used to predict the consequences of alternative strategies. Following this and each step, it is important to refer back to the previous steps to ensure coherence and consistency.

3. Alternative strategies. Once the objectives have been identified, the next step is to identify alternative management actions that may be combined into strategies for achieving fundamental objectives. Long, exhaustive lists of possible actions can be quite useful for realizing a creative and robust solution to a complex conservation problem. Partners are therefore encouraged to include alternatives that might otherwise appear at face value to be infeasible or too costly. These individual actions can then be combined into several categories and then into alternative strategies so that they can be compared in a feasible manner. Including the current, status quo strategy is useful as a baseline from which to compare other alternative strategies. From this set of alternative strategies, an optimal choice will be identified in step 5 .

4. Consequences. With the conceptual elements of the problem in place, i.e., fundamental objectives and the alternatives to achieving those objectives, the next step is to develop a conceptual decision model, or influence diagram, that links these elements. 
An influence diagram forms the basis for a series of quantitative predictive models that provide the backbone for a decision analysis (Howard 1988). Such quantification enables explicitness and transparency in showing the steps involved in arriving at a particular decision. It is worth noting here a key difference between SDM and conceptual approaches to solving conservation problems. For quantitative prediction and modeling, a measureable attribute for each objective and driver is required. Whenever possible, existing numerical models and existing literature should be used to estimate magnitudes of external drivers and to predict consequences for the objectives. Expert elicitation is a useful approach to providing quantitative predictions, especially when time is limited or no existing literature or numerical models are compatible with the decision model (Kuhnert et al. 2010). There is often much uncertainty surrounding each quantified external driver and predicted consequence, and these can be captured from available literature, numerical models, or variation among expert-elicited input. An influence diagram populated with quantities using one of the methods described here is a crucial step toward identifying an optimal decision and evaluating its robustness to uncertainties regarding the external drivers and predicted consequences.

5. Trade-offs and optimization. SDM in a collaborative context very often includes multiple fundamental objectives because of the diverse values of the stakeholders involved. In this step, these competing objectives are weighed, i.e., traded off, as a key step toward identifying an optimal decision from the set of alternatives. Many approaches are available to weigh objectives, but they all involve eliciting the values that the decision maker and/or stakeholders place on each of the fundamental objectives. Swing weighting is a useful technique for eliciting objective weights while accounting for the range of consequences (Von Winterfeldt and Edwards 1986). To identify a recommended management alternative, the predicted consequences should be weighed according to the levels of importance ascribed by the relevant stakeholders. There are also many methods to identify an optimal strategy, and the selected method should match the class of problem. For example, many multicriteria decisionanalytic tools are available for solving decision problems with multiple fundamental objectives, but a subset of these are suited for problems for which probabilities have been assigned to the external driver scenarios and predicted consequences.

6. Sensitivity, robustness, and value of information. Often considered as an extra step following the core steps of PrOACT, this step is important for the decision makers to buy into the process and feel confident that the optimal decision has been fully evaluated. Uncertainties about not only the external drivers and predicted consequences but also about the trade-offs among fundamental objectives often impede following a single recommendation without fully evaluating its robustness to these uncertainties. The optimal decision may depend on many possible sources of uncertainty, but the sources of uncertainty important for decision making are often unknown before conducting all six SDM steps. Often a decision maker would like to know whether an optimal decision would change if assumptions within the decision model were changed or if new information was discovered. A sensitivity analysis can be conducted to evaluate the robustness of an optimal decision, i.e., whether it changes when assumptions are altered regarding external drivers, predicted consequences, and/or trade-offs between objectives. Such a sensitivity analysis allows for calculating the value of perfect information (Runge et al. 2011a), which can be used to guide needs for gathering new information.

Recognizing the complexity of the problem, we used a prototyping approach (Blomquist et al. 2010, Starfield and Jarre 2011, Schrage 2013), also known as decision sketching (Gregory et al. 2012) or as appraisal of a decision basis (Howard 1988), to generate an initial decision-analytic framework that is intended to give decision makers guidance for decision making across SFB and to identify needs for future refinements. The initial prototype is intended to capture and assemble the main elements of the decision problem, followed by a sensitivity analysis to identify irrelevant objectives (see Appendix 1); dominated alternatives, i.e., those that cannot be chosen as optimal regardless of the trade-offs; and information gaps having the largest influence on the recommended decision (Blomquist et al. 2010, Starfield and Jarre 2011).

\section{RESULTS}

\section{Problem framing}

The initial task of our team was to identify and state the extent of the overarching problem to address. For our problem, we could not identify an individual or single institutional decision maker that was responsible for all decisions about tidal marsh restoration, management, and protection in SFB. Instead, we worked with an array of stakeholders including federal, state, and local natural resource managers, planners, and policy makers. We did not include civil society during this initial effort because very few tidal marsh areas in SFB are privately held or managed. We invited five resource managers, five planners, and five scientists who represented a wide array of stakeholders (Table 1).

We discussed concerns of stakeholders regarding tidal marsh quality, quantity, and connectivity especially for endangered species or species of concern to support their long-term recovery and survival. We also discussed potential key uncertainties including the rate and extent of SLR to 2100, changes in storm frequency and intensity, and tidal marsh ecosystem response to changing conditions, e.g., whether marsh accretion can keep up with SLR. In addition, we discussed the level of uncertainty regarding where and when management actions could contribute to the persistence of the tidal marshes and their ecosystem services. We developed a single decision question that best captured the primary concerns of the stakeholders: To conserve San Francisco Bay tidal marshes in light of future climate change, what management, restoration, and protection actions, if any, should be conducted, and where, when, and how should they be conducted?

\section{Objectives and drivers}

Within the context of our decision question, we listed several possible draft objectives based on the concerns and values of team members and the organizations they represented (Table A1.1). This initial list was then organized in a means-ends network to identify relationships among objectives (Fig. 2). This 
Table 1. Organizations, positions, and roles of team members who manage and restore tidal marshes for the San Francisco Bay, California, USA estuary.

Organization $\quad$ Position

SDM coaches

USGS Western Ecological Research Center

USFWS Endangered Species Office

University of Vermont

Stakeholders

USFWS Sacramento Field Office

USFWS Region 8 Inventory and Monitoring

California State Coastal Conservancy

Bay Cons. \& Development Comm.

California State Coastal Conservancy

SFB Joint Venture

U.S. Army Corps of Engineers

San Francisco Bay Joint Venture

USFWS SFB National Wildlife Refuge

California Department of Fish and Game

Scientists

USGS Western Ecological Research Center

USGS Western Ecological Research Center

USGS Western Ecological Research Center
Position

Research ecologist

Endangered species biologist

$\mathrm{PhD}$ candidate

Recovery biologist

Inventory and monitoring biologist

Climate change manager

Chief deputy director, climate change

Deputy director

Joint Venture coordinator

Environmental planner

Science coordinator

Project leader

Area biologist

Research wildlife biologist

Research ecologist

South Bay salt ponds lead scientist

Fig. 2. Draft means-ends network showing relationships among objectives for maximizing the resilience of functions and ecosystem services for tidal marshes of San Francisco Bay. Bolded boxes indicate draft fundamental objectives (i.e., "ends"); unbolded boxes indicate means objectives.

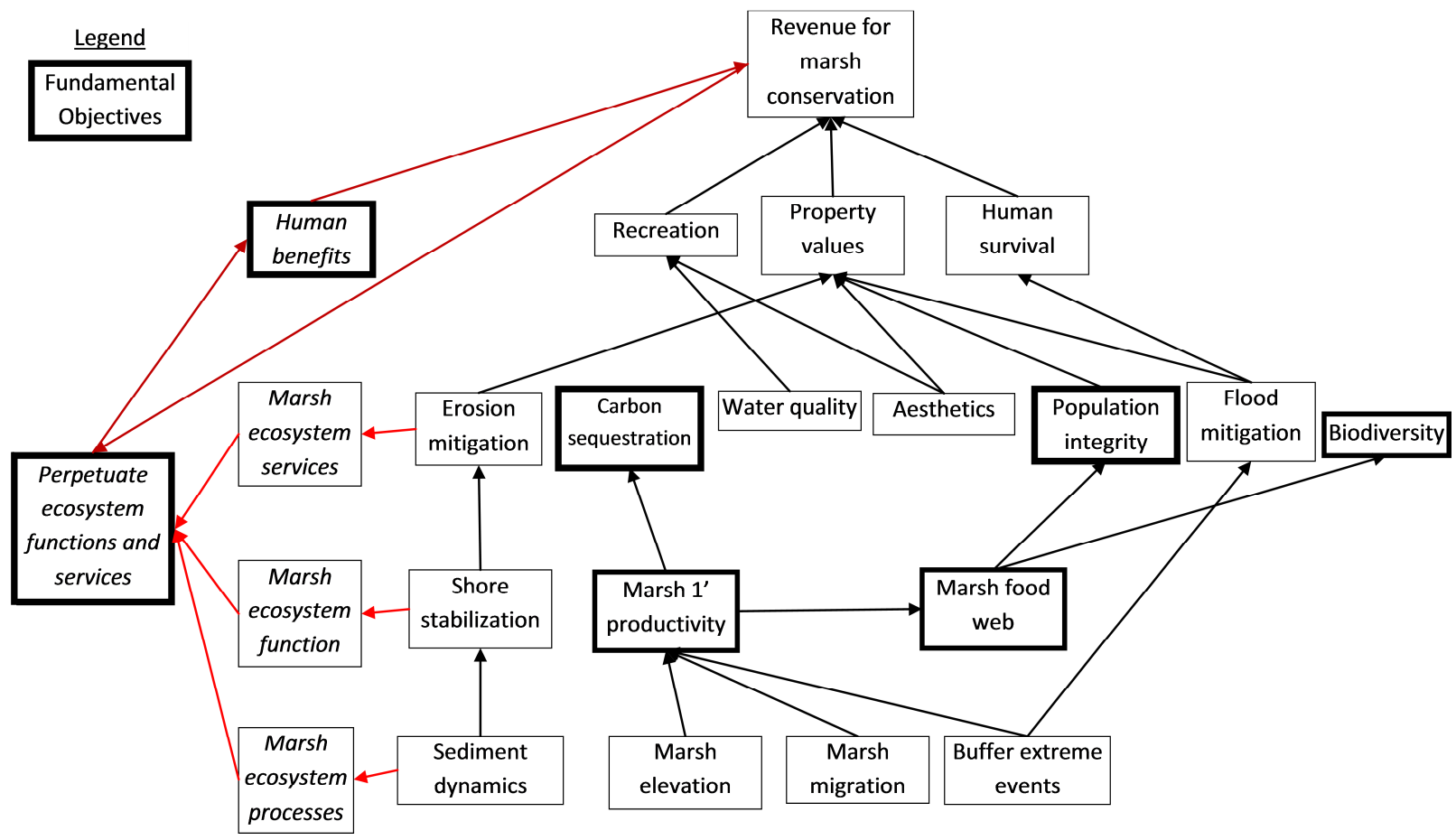


diagram helped distinguish fundamental objectives, i.e., ultimate desired end points of conservation, from means objectives, i.e., intermediate steps needed to achieve the fundamental objectives. The means-ends diagram also facilitated categorizing the draft objectives into ecosystem processes, services, and functions as well as the human benefits of conserving tidal marshes (Table 2). We summarized the draft objectives within an overarching objective statement: to perpetuate marsh ecosystem function and services, and human benefits by maximizing resilience to climate change. For this prototype SDM process we chose a subset of the possible fundamental objectives: maximize marsh ecosystem integrity, maximize likelihood of California Ridgway's Rail (Rallus obsoletus obsoletus), previously known as the California Clapper Rail (Rallus longirostris obsoletus), recovery as an example for endangered species recovery, and maximize human benefits from tidal marshes (Table 2).

Table 2. Classification of objectives for tidal marsh conservation and restoration with future climate change in San Francisco Bay, California, USA.

\begin{tabular}{|c|c|c|c|}
\hline $\begin{array}{l}\text { Ecosystem } \\
\text { Processes }\end{array}$ & $\begin{array}{l}\text { Ecosystem } \\
\text { Functions }\end{array}$ & $\begin{array}{l}\text { Ecosystem } \\
\text { Services }\end{array}$ & Human Benefits \\
\hline $\begin{array}{l}\text { Maintenance of } \\
\text { marsh elevations }\end{array}$ & Refugia & $\begin{array}{c}\text { Flood } \\
\text { mitigation }\end{array}$ & $\begin{array}{l}\text { Recreation, } \\
\text { angling, } \\
\text { swimming }\end{array}$ \\
\hline $\begin{array}{l}\text { Ability to buffer } \\
\text { extreme events }\end{array}$ & Diversity & $\begin{array}{c}\text { Carbon } \\
\text { sequestration }\end{array}$ & $\begin{array}{c}\text { Homes, property } \\
\text { values }\end{array}$ \\
\hline Marsh migration & $\begin{array}{l}\text { Nesting and } \\
\text { foraging }\end{array}$ & Water quality & $\begin{array}{l}\text { Commercial } \\
\text { fisheries }\end{array}$ \\
\hline \multirow[t]{2}{*}{$\begin{array}{l}\text { Sediment } \\
\text { dynamics }\end{array}$} & $\begin{array}{l}\text { Primary } \\
\text { production }\end{array}$ & & $\begin{array}{l}\text { Support } \\
\text { economy }\end{array}$ \\
\hline & $\begin{array}{c}\text { Nursing/ } \\
\text { spawning } \\
\text { habitat } \\
\text { Aquatic food } \\
\text { web } \\
\text { Terrestrial food } \\
\text { web }\end{array}$ & $\begin{array}{l}\text { Shoreline } \\
\text { stabilization }\end{array}$ & Aesthetics \\
\hline
\end{tabular}

\section{Alternative strategies}

We developed five management categories containing actions that could be undertaken by stakeholders (Table 3). Because availability of funding and personnel for implementing actions were considered finite, the team did not create an exhaustive list of possibilities, but rather a list of what they thought were important actions for this CDA. Three categories of actions were focused on ways of adapting tidal marsh management to improve resiliency and better prepare for the impacts of SLR and storminess: resilient restoration, migration restoration, and wildlife adaptation (Table 3 ). In addition to these categories, we also included no action and a static restoration action that were used for comparison with the alternative strategies focused on climate change. These categories provided the basis for developing resource allocation scenarios among these action categories (Fig. 3). Because SLR projections are relatively confident over the next few decades (Cayan et al. 2009, Kettle 2012), we focused on developing alternative management strategies to address not only the expected effects of SLR but also the great uncertainty associated with frequency of intense storms from 2012 through 2050 .

The set of alternative allocation strategies consisted of four ways to allocate resources among categories of actions through time (Fig. 3). Status quo represents the current ongoing strategy used by SFB stakeholders and would allocate approximately $70 \%$ of resources toward static restoration efforts with minimal consideration of climate change (Fig. 3A). A second alternative allocation strategy, marsh migration, would initially entail resilient restoration actions in current marsh areas but later would focus on areas that would provide the possibilities of landward migration of marshes via migration restoration (Fig. 3B). Third, the climate-smart restoration (Stein et al. 2014) strategy would resemble the marsh migration strategy except that allocation to climate restoration actions would remain dominant from 2015 through 2050 (Fig. 3C). As a fourth alternative allocation strategy, climate restoration sans wildlife would resemble climate-smart restoration, except the entire $10 \%$ allocation toward wildlife adaptation actions would be eliminated by 2015 (Fig. 3D). Our final management strategy was the option of do nothing, which we defined as allocating no resources toward any tidal marsh conservation or management actions.

Fig. 3. Contrasting strategies of allocating limited resources, i. e., staff time and management funds, among categories of actions to conserve or restore tidal marshes in San Francisco Bay through 2050. Strategies B-D explicitly address uncertainties regarding sea-level rise and extreme storm events.
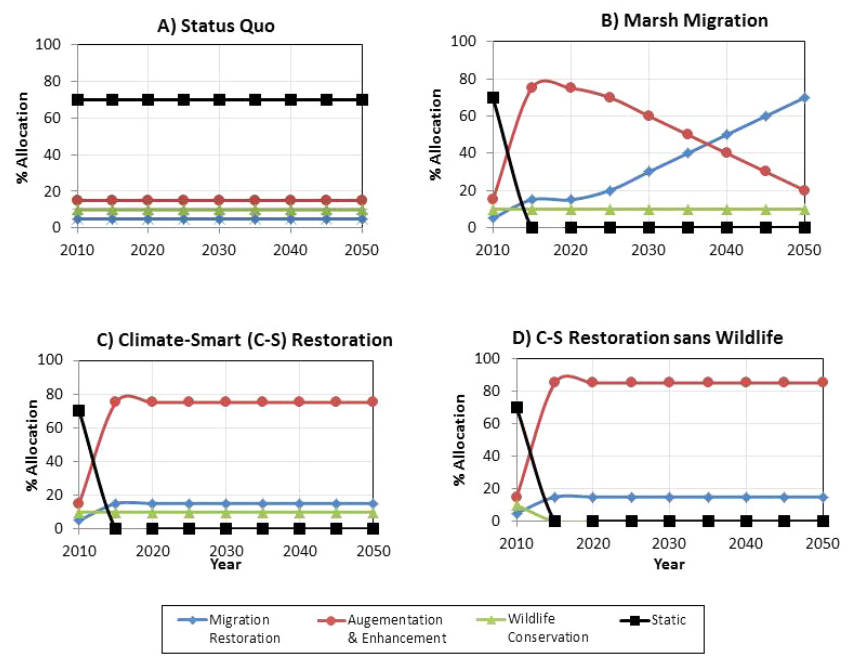

\section{Consequences}

After developing an influence diagram (Fig. 4), we identified a suite of measureable attributes for each element of the decision model. The influence diagram provided a platform by which we could represent conceptually how the alternative allocation strategies (Fig. 3; marsh migration, climate restoration sans wildlife, climate-smart restoration, do nothing, and status quo) would affect the fundamental objectives to maximize marsh ecosystem integrity, likelihood of California Ridgway's Rail recovery, and human benefits from tidal marshes (see Table 4). 
Table 3. Five categories that contain management actions were developed by a team of decision makers, stakeholders, and scientists to address climate change effects on conservation and restoration of tidal marshes in San Francisco Bay, California, USA.

\begin{tabular}{|c|c|c|}
\hline Action category & Reasoning & Actions \\
\hline No Action & $\begin{array}{l}\text { In light of climate change effects, the benefits of restoration } \\
\text { and management actions in tidal marshes may be diminished. } \\
\text { Thus, we considered the option of stopping all current and } \\
\text { planned restoration projects. }\end{array}$ & All restoration and management activities would stop. \\
\hline Static Restoration & $\begin{array}{l}\text { Pursue existing tidal marsh goals, as outlined in Goals Project } \\
\text { 1999, with nominal consideration of climate change in } \\
\text { implementation and planning. It was recognized that the term } \\
\text { "status quo" is not truly reflective of current practice, as } \\
\text { many project managers in SFB have begun incorporating } \\
\text { climate change strategies into their policy and planning } \\
\text { processes. However, we used the term to evaluate limited } \\
\text { consideration of climate change. }\end{array}$ & $\begin{array}{l}\text { Management and restoration activities would continue as they are } \\
\text { currently occurring with limited consideration of climate change } \\
\text { effects. }\end{array}$ \\
\hline $\begin{array}{l}\text { Resilient } \\
\text { Restoration }\end{array}$ & $\begin{array}{l}\text { Restoration actions to increase resiliency of tidal marshes to } \\
\text { climate change effects. Potential actions included exploring } \\
\text { engineering options to improve resilience of future or past } \\
\text { tidal restoration efforts to sea-level rise and storms, } \\
\text { improving the health of existing tidal marshes, and increasing } \\
\text { understanding through biophysical modeling of tidal marsh } \\
\text { response to climate change. }\end{array}$ & $\begin{array}{l}\text { Pilot projects would be developed to evaluate engineering } \\
\text { solutions for future restorations, to retrofit ongoing or past } \\
\text { projects, or to enhance historic marsh. Tidal marsh restoration } \\
\text { projects require flexibility to facilitate climate adaption (e.g., } \\
\text { build levees bayward with gradual slope for movement, consider } \\
\text { adjacent property options, flood control and water treatment } \\
\text { projects) for near ( } 20 \text { - 50yr) and long-term (> 50yr) time frames. } \\
\text { It would be necessary to accelerate the timeline for tidal marsh } \\
\text { restoration, use upland fill to raise marsh elevations, and to } \\
\text { restore marshes with the highest accretion potential. }\end{array}$ \\
\hline $\begin{array}{l}\text { Migration } \\
\text { Restoration }\end{array}$ & $\begin{array}{l}\text { Actions that would allow marshes to move with sea-level } \\
\text { rise. Alternatives include identifying and prioritizing areas } \\
\text { where tidal marshes could migrate, acquiring open lands } \\
\text { adjacent to existing tidal marsh, and removing infrastructure } \\
\text { barriers to marsh transgression. }\end{array}$ & $\begin{array}{l}\text { Upslope areas would be mapped and prioritized for acquisition to } \\
\text { allow vertical and horizontal marsh transgression. Acquired } \\
\text { upslope areas would be managed with rolling easements, rather } \\
\text { than a fee title. Where feasible, development and infrastructure } \\
\text { barriers, e.g., levees, would be removed or evaluated to facilitate } \\
\text { marsh expansion and to assess ecosystem response. }\end{array}$ \\
\hline Wildlife Adaptation & $\begin{array}{l}\text { Increase resiliency of marsh dependent wildlife species of } \\
\text { management and conservation concern in response to climate } \\
\text { change. }\end{array}$ & $\begin{array}{l}\text { It is necessary to minimize stressors on marsh wildlife, including } \\
\text { invasive and nuisance species, predators, and contaminants. Other } \\
\text { potential actions include captive breeding or translocation } \\
\text { programs for important management species, including federally } \\
\text { threatened and endangered species, or the creation of artificial } \\
\text { habitat elements and structure to improve species resilience. }\end{array}$ \\
\hline
\end{tabular}

Table 4. Measureable attributes of fundamental objectives considered for tidal marsh conservation and restoration with future climate change in San Francisco Bay, California, USA.

\begin{tabular}{|c|c|c|c|}
\hline Variable name & Description & Low & High \\
\hline \multicolumn{4}{|l|}{ External factors } \\
\hline Extreme events & Annual frequency of extreme storm events 2011-2050 & $0-1$ & $2-5$ \\
\hline Budget 2011-2020 & $\begin{array}{l}\text { Available funds (Millions) for management and } \\
\text { restoration 2011-2020 }\end{array}$ & $60-299$ & $300-400$ \\
\hline \multicolumn{4}{|l|}{ Fundamental objectives } \\
\hline $\begin{array}{l}\text { California Ridgway's Rail (Rallus obsoletus } \\
\text { obsoletus) recovery } 2020\end{array}$ & $\begin{array}{l}\text { Success in meeting all habitat requirements in recovery } \\
\text { plan in } 2020\end{array}$ & Unrecovered & Recovered \\
\hline California Ridgway’s Rail recovery 2050 & $\begin{array}{l}\text { Success in meeting all habitat requirements in recovery } \\
\text { plan in } 2050\end{array}$ & Unrecovered & Recovered \\
\hline Marsh ecosystem index 2020 & $\begin{array}{l}\text { Integrates condition of } 5 \text { ecosytem components in } 2020 \text {, } \\
\text { independent of Ridgway's Rail habitat requirements }\end{array}$ & $0-3$ & $4-5$ \\
\hline Marsh ecosystem index 2050 & $\begin{array}{l}\text { Integrates condition of } 5 \text { ecosytem components in } 2050 \text {, } \\
\text { independent of Ridgway's Rail habitat requirements }\end{array}$ & $0-3$ & $4-5$ \\
\hline Human benefit 2020 & $\begin{array}{l}\text { Integrates risks in } 2020 \text { for disease transmission, } \\
\text { flooding losses, and recreational opportunities }\end{array}$ & $0-1$ & $2-3$ \\
\hline \multicolumn{4}{|l|}{ Means objective } \\
\hline Budget 2021-2050 & $\begin{array}{l}\text { Available funds (Millions) for management and } \\
\text { restoration 2021-2050 }\end{array}$ & $300-700$ & $800-1000$ \\
\hline
\end{tabular}


Fig. 4. Influence diagram for conservation of tidal marshes in San Francisco Bay, California, USA. This conceptual decision model links alternative strategies (hexagon) to fundamental objectives (rectangles) via an external driver (rounded rectangle) and an intermediate driver or means objective (oval). Solid arrows indicate effects occurring during the short-term (2020) and the longer term (2050) response horizons; dashed arrow indicates an effect modeled only during the long-term; circular arrows indicate that the levels for each of these factors at 2020 were considered as one of the predictors of the outcomes for the same factor in 2050, for example, low marsh integrity 2012-2020 would result in a greater likelihood of low integrity 2021-2050 than if integrity were high through 2020.

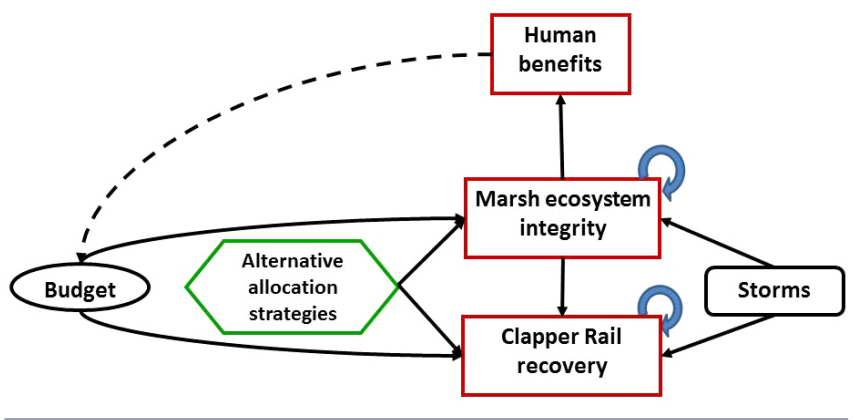

We identified two time horizons of management concern at which most of the fundamental objectives would be evaluated: a shortterm horizon at 2020 and a longer term horizon at 2050, which were based on current planning and response horizons for restoration projects already in progress and for implementation of new projects under consideration (Nicholls 2004, Bell et al. 2007, Stralberg et al. 2011, McCarthy et al. 2012, Veloz et al. 2013).

We developed predictive models to enable comparison of our alternative resource allocations in a more transparent and robust manner, quantified each of these relationships, and incorporated measures of uncertainty by constructing a Bayesian decision network (BDN; Fig. 5) using Netica 4.16 (Norsys Software Corp, Vancouver, British Columbia, Canada; http://www.norsys.com/). The BDN provided a graphical representation and enabled analysis of probabilistic relationships between our alternative strategies, fundamental objectives, and external influences (Henrion et al. 1991). In particular, our parameterized BDN provided a platform to estimate likelihoods of outcomes for California Ridgway's Rail recovery, marsh integrity, and human benefits as a function of alternative tidal marsh management strategies and external influences of budget and storms. Details regarding the measurable attributes, parameterization, and sensitivity analysis are found in Appendix 1. The Netica file containing the BDN can be accessed in Appendix 2 .

When comparing consequences of the climate-smart restoration allocation with consequences of the other allocation scenarios, we found the greatest levels of (1) likelihood of California Ridgway's Rail recovery for both management response horizons ( 0.53 at 2020 and 0.55 at 2050); (2) marsh integrity index at 2020 ( 2.82 out of 5); and (3) human benefit index at 2020 (1.21 out of 3; Table 5). The marsh migration allocation yielded the highest predicted marsh integrity index at 2020 (2.93 out of 5). Predicted likelihoods for the outcomes in terms of the fundamental objectives exhibited substantial variation among the alternative allocation strategies, with do nothing and climate-smart restoration having the lowest and highest predictions, respectively, for every fundamental objective (Table 5). Likelihood of California Ridgway's Rail recovery at both response horizons exhibited the most variation between the extremes, i.e., $97 \%$ difference between do nothing and climate-smart restoration, whereas human benefit in 2020 showed the least variation between these strategies: a $4 \%$ difference. The panel estimated a 0.9 probability that extreme storm events would occur more than twice annually from 2012 to 2050 (Table 5). The 2021-2050 budget showed very little variation among alternative strategies. This can be explained by the corresponding lack of variability in its primary driver, 2020 human benefit (Table 5).

\section{Trade-offs and optimization}

Utilities assigned by stakeholders representing how they valued each possible outcome, except for the worst possible (utility $=0$ ) and best possible (utility $=100$ ) outcomes, ranged from 12 to 87 under the baseline parameterization (Appendix 1, Table A1.2). The lower utility represented a scenario in which all outcomes were pessimistic except for marsh integrity in 2050, whereas the higher utility reflected all optimistic outcomes except for California Ridgway's Rail recovery by 2020 . The likelihood of California Ridgway's Rail recovery received the lowest importance weight $(0.17)$ and was exceeded by human benefit index in 2020 and marsh integrity in 2020 and 2050, with California Ridgway's Rail recovery in 2050 having the greatest importance weight (0.27; Table 5).

According to the baseline parameterization, the climate-smart restoration allocation (defined in Fig. 3C) had the greatest expected utility, although its confidence interval overlapped the other allocations except for do nothing (Fig. 3D). The climatesmart restoration was optimal regardless of nearly every assumption regarding knowledge about the system and for every advocacy scenario (Fig. 3). Allocations that addressed SLR and storm effects consistently yielded more positive outcomes than did the do nothing or status quo allocation management scenarios (Table 5), neither of which was optimal under any assumption regarding knowledge about the system nor any of the advocacy scenarios.

\section{DISCUSSION}

We used a collaborative decision-analytic approach by following a SDM process to identify a strategy to allocate limited resources for conservation of SFB tidal marsh by a diverse set of stakeholders. We investigated how stakeholders' values influenced their decision making and how they viewed trade-offs, and identified an optimal strategy that is robust to the focal sources of uncertainty.

Can a CDA approach lead to consensus among a diverse set of decision makers responsible for environmental stewardship and faced with uncertainties about climate change, funding, and stakeholder values?

The SFB is an excellent example of a system demonstrating socialecological complexity in terms of the diverse stakeholders and concomitant concerns regarding managing for tidal marsh resilience along with uncertainty (Goals Project 2000). Involving 
Fig. 5. A Bayesian decision network showing averages of elicited model predictions and computed expected utilities of alternative management allocations for conservation and of tidal marshes in San Francisco Bay. Predicted probabilities of possible management outcomes are given as percentages next to the histogram for each stochastic node (green box) and are averaged across alternative allocations. A mean \pm SD is also provided as a computed prediction for each stochastic node that is a continuous variable and has been discretized for the decision analysis. The utility node integrates the five fundamental objectives (indicated by incoming arrows) and contains the elicited utilities from panel experts. Storm frequency and 2011-2020 budget represent external factors; the 2021-2050 budget is a means objective. Climate-Smart Restoration has the highest expected utility and therefore was recognized as the best strategy to manage for tidal marsh resilience and California Ridgeway's Rail, formerly California Clapper Rail, recovery while accounting for human benefits.

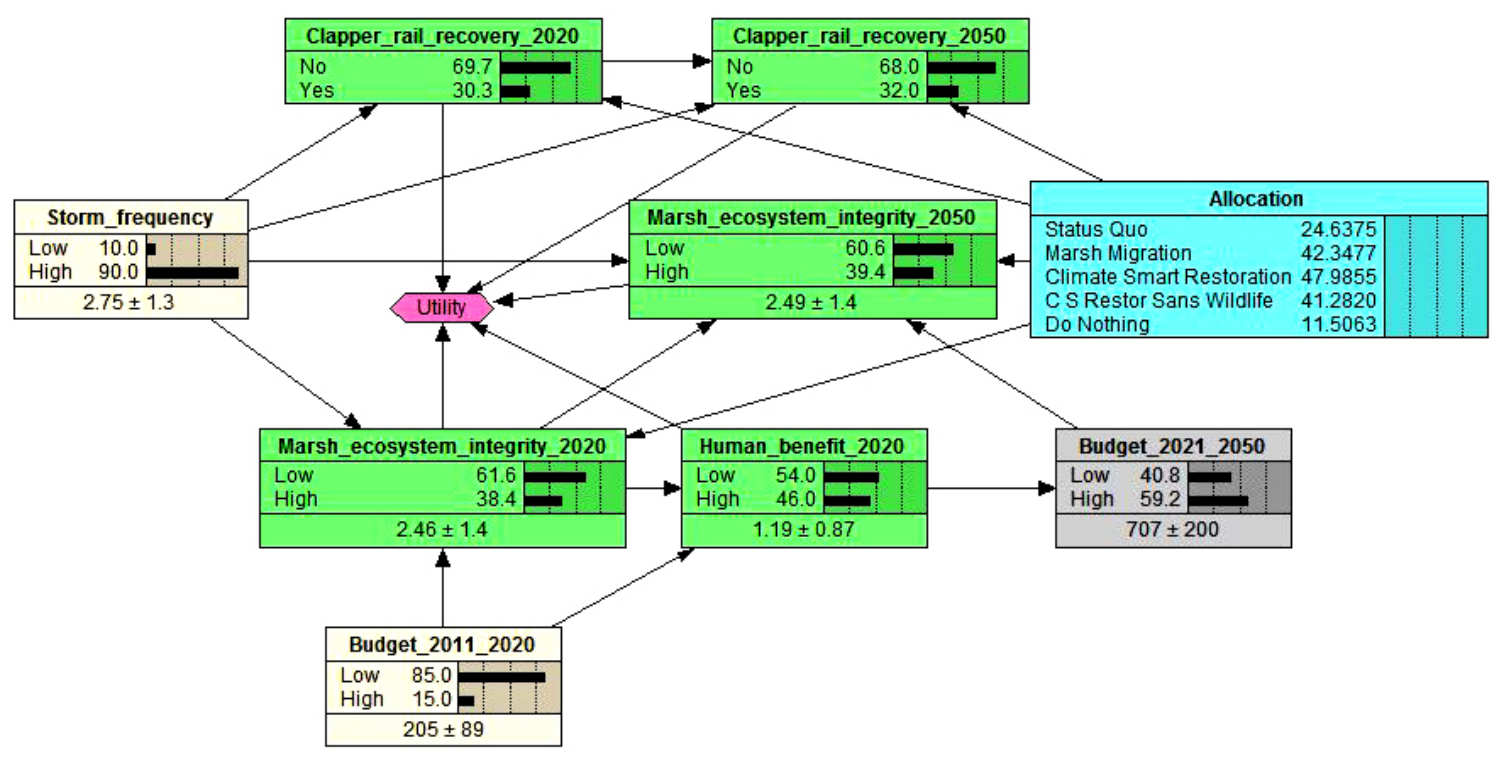

relevant stakeholders and technical experts is crucial for generating robust decision-analytic frameworks that are ultimately implemented on the ground, and this team approach is especially important when dealing with many jurisdictions (e.g., Arkema et al. 2006, Levin et al. 2009). The structure and parameterization of our decision-analytic framework, including the elicited utility values, were based on the collective input of our team (Goals Project 2000). By involving a subset of stakeholders in our prototype SDM process, we were able to quickly develop a BDN that incorporates multiple sources of uncertainty and a representative set of objectives that are relevant for SFB decision making. Through this transparent process, consensus was reached that continuing restoration projects as currently planned without explicit climate change adaptation is much less preferred than strategies that anticipate future SLR and storms. Consensus was also reached that it is worth continuing to invest in restoration efforts, especially if they explicitly account for SLR and storms.

We believe such a prototyping approach will lead to a more widely accepted and implementable strategy faster than if we had tried to incorporate additional complexity by integrating other objectives and uncertainties. Involving a broader set of stakeholders, e.g., project-specific land managers, local municipalities, and civil society, and additional technical advisors would enable refinement of the decision-analytic framework to ensure its robustness and increase acceptance of the chosen management strategies. Involving a broader set of experts would enable explicit incorporation of additional system components of concern, such as other intertidal habitats, e.g., tidal flats, and other highprofile endangered species, e.g., the salt marsh harvest mouse (Reithrodontomys raviventris; Goals Project 2000).

What is an optimal strategy for the conservation of tidal marshes and what strategy is robust to aforementioned uncertainties?

For achieving desired social and ecological objectives over the next four decades, we found that an immediate shift of investment from more traditional tidal marsh restoration activities to those focused more directly on mitigating effects of SLR and storms, i.e., climate-smart restoration (Stein et al. 2014), would be most beneficial in SFB. This finding was robust to substantial levels of uncertainty about system dynamics and management responses over multiple time scales, and also to considerable variability in elicited utilities among stakeholders.

A factor that limits the ability to make predictions about the multifaceted response of tidal marsh to environmental and manmade drivers is the unavailability of a measurable index that incorporates the multiple elements of concern regarding marsh ecosystem functions and processes. In our prototype, we proposed a marsh ecosystem index consisting of measurable attributes, e.g., marsh area, species richness, and accretion capacity, that could be monitored to assess management actions (Table 3). This index of marsh integrity, once refined, would 
Table 5. Predicted outcomes under alternative temporal allocations of management dollars to conserve or restore tidal marshes in the San Francisco Bay, California, USA. Predictions presented as mean \pm standard deviation. Rail = California Ridgway's Rail $($ Rallus obsoletus obsoletus).

\begin{tabular}{|c|c|c|c|c|c|c|c|c|c|c|c|c|c|}
\hline \multirow{2}{*}{$\begin{array}{l}\text { Alternative allocation } \\
\text { Do Nothing }\end{array}$} & \multirow{2}{*}{$\begin{array}{c}\begin{array}{c}\text { Likelihood of } \\
\text { Rail recovery } \\
\text { by } 2020\end{array} \\
0.01\end{array}$} & \multirow{2}{*}{$\begin{array}{c}\begin{array}{c}\text { Likelihood of } \\
\text { Rail recovery by } \\
2050\end{array} \\
0.02\end{array}$} & \multicolumn{3}{|c|}{$\begin{array}{l}\text { Marsh integrity } \\
\text { index in } 2020^{\dagger}\end{array}$} & \multicolumn{3}{|c|}{$\begin{array}{c}\text { Marsh integrity } \\
\text { index in } 2050^{\dagger}\end{array}$} & \multicolumn{2}{|c|}{$\begin{array}{l}\text { Human benefit } \\
\text { index in } 2020^{\ddagger}\end{array}$} & \multicolumn{3}{|c|}{$\begin{array}{c}\text { Budget }(\$ M)^{\S} \\
2020-2050\end{array}$} \\
\hline & & & 1.90 & \pm & 1.2 & 1.68 & \pm & 1.1 & 1.16 & $\pm \quad 0.87$ & 706 & \pm & 200 \\
\hline Status Quo & 0.19 & 0.18 & 2.26 & 1 & 1.4 & 2.21 & \pm & 1.4 & 1.18 & \pm 0.87 & 707 & \pm & 200 \\
\hline Marsh Migration & 0.38 & 3 & 2.64 & \pm & 1.5 & 2.93 & \pm & 1.4 & 1.20 & \pm 0.87 & 708 & \pm & 200 \\
\hline Climate Restoration & 0.53 & 5 & 2.82 & \pm & 1.4 & 2.89 & \pm & 1.4 & 1.21 & \pm 0.87 & 708 & \pm & 200 \\
\hline $\begin{array}{l}\text { Climate Restoration Sans } \\
\text { Wildlife }\end{array}$ & 0.41 & 0.43 & 2.68 & \pm & 1.5 & 2.72 & \pm & 1.5 & 1.20 & \pm 0.87 & 708 & \pm & 200 \\
\hline $\begin{array}{l}\text { Average prediction } \\
\text { Importance weight }\end{array}$ & $\begin{array}{l}0.30 \\
0.14\end{array}$ & $\begin{array}{l}0.32 \\
0.27\end{array}$ & $\begin{array}{l}2.46 \\
0.21\end{array}$ & \pm & 1.4 & $\begin{array}{l}2.49 \\
0.20\end{array}$ & \pm & 1.4 & $\begin{array}{l}1.19 \\
0.17\end{array}$ & \pm 0.87 & $\begin{array}{l}707 \\
\text { NA }\end{array}$ & \pm & 200 \\
\hline \multicolumn{14}{|c|}{$\begin{array}{l}\text { Marsh integrity index was scored on a scale of } 0-5 \text {, with } 5 \text { being the highest predicted level of integrity. } \\
\text { Human benefit index was scored on a scale of } 0-3 \text {, with } 3 \text { being the highest predicted level of human benefit. } \\
\text { Long-term budget is a means objective defined as available US dollars (in millions) for conducting tidal marsh management and restoration, } \\
\text { including needed equipment, travel, and personnel costs. In the Bayesian Decision Network, it was defined as a function of human benefits in } 2020 . \\
\text { The Do Nothing and Status Quo allocations were dominated alternatives, as the predicted probabilities of optimistic outcomes were equal to or } \\
\text { less than those of at least one other allocation. As such, they cannot be optimal decisions regardless of the elicited utilities. } \\
\text { Averaged predictions across the five alternative allocations. } \\
\text { Importance weight for each fundamental objective calculated based on elicited utility values using Simple Multiattribute Rating Technique } \\
\text { (Hammond et al. 1999). }\end{array}$} \\
\hline
\end{tabular}

enable constructing new models or refining existing ones for predicting the response of tidal marsh to climate drivers and management strategies (Stralberg et al. 2011). Specifying additional categories of tidal marsh response would necessitate another round of sensitivity analyses to evaluate the value of collecting more information to update predicted outcomes for tidal marsh integrity under alternative management strategies, budgets, and climate scenarios (see Appendix 1). Identifying highvalue uncertainties would form the basis of future research endeavors and possibly an adaptive management program (Runge et al. 2011a).

Although general habitat requirements are understood for most tidal marsh wildlife species under current conditions, quantifying their response to management actions and climate change effects remains a challenge (Thorne et al. 2012). However, developing a transparent framework to conserve species occurring throughout the SFB, e.g., California Ridgway's Rail, would require coordinating these actions among projects based on predictive models linking the consequences of project-scale actions to SFBwide outcomes. Using expert elicitation in the absence of predictive models, however, can help identify modeling needs by targeting the high-value sources of uncertainty. For example, our analysis indicated that optimality of the climate-smart restoration scenario was robust to uncertainty about California Ridgway's Rail recovery over the next four decades.

Over the past decade, there have been increasing calls for action to better address and manage for resilience to the effects of climate change on ecosystem services and human communities (Kettle 2012, Thorne et al. 2012). Public support for expenditures to conserve or restore these ecosystems may decrease if the benefits to human health and well-being are poorly addressed (Fujita et al. 2013). Our team of diverse stakeholders who want to manage for tidal marsh resilience believed that diverse ecosystem services should be considered, including plant productivity, sediment trapping, improved water quality, carbon sequestration, and flood mitigation (Duarte et al. 2013). In addition to this ecosystem service accounting, the team also emphasized the importance of maintaining habitats for at-risk wildlife that rely on tidal marshes such as the endangered California Ridgway's Rail. Based on our findings, shifting resources from traditional marsh restoration to climate-smart restoration actions would provide the greatest positive outcomes through 2050.

\section{CONCLUSION}

Our project was the first application of CDA to assist SFB stakeholders in managing for tidal marsh resilience while incorporating uncertainty about future climate change effects and available funding. The process helped to build consensus across an interdisciplinary team by enabling agreement on an overarching objective: to perpetuate marsh ecosystem function and services and human benefits by maximizing resilience to climate change. A single decision question best captured the primary concerns of stakeholders: To conserve San Francisco Bay tidal marshes in light of future climate change, what management, restoration, and protection actions, if any, should be conducted, and where, when, and how should they be conducted? Through a transparent process, consensus was reached that continuing restoration projects as currently planned, i.e., the status quo, without explicit climate change adaptation built into the process, and stopping restoration efforts altogether, i.e., doing nothing, were much less preferred than strategies that anticipate future climate change. Consensus was then reached that it is worth continuing to invest in restoration efforts that explicitly account for future climate change, i.e., climate-smart restoration and marsh migration. This shared understanding will increase the likelihood of maximizing resilience and increase the probability of conservation in light of a highly uncertain future across the SFB landscape.

The SDM approach allowed us to consider social concerns and scientific uncertainty explicitly by having key partners work 
together to discuss their shared issues. Because a decision model was specified, the process became more transparent and aided the ability of partners to learn from and refine the framework for future applications, which may be used to support funding decisions. This approach adds value when decisions need to be made in light of uncertainty and within complex ecosystems. The outcome of this exercise was not viewed as a final result, but instead as a first prototype to address a complex problem. Future directions include modifying the decision-analytic framework by engaging a broader range of stakeholders, civil society experts, and technical experts to refine the spatial scale of the decision model while incorporating more issues, e.g., sediment availability; species of concern, e.g., the salt marsh harvest mouse; and modeling strategies with SLR and storms extending beyond 2050. In addition, the framework should help to identify future adaptive management needs that can update and improve the decision model in future iterations. Not only does this decision-analytic framework provide a basis for refinement and application in the $\mathrm{SFB}$, it provides a potential jump start for conservation partners struggling with collaborative decision making in other ecosystems.

Responses to this article can be read online at: http://www.ecologyandsociety.org/issues/responses. $\mathrm{php} / 7018$

\section{Acknowledgments:}

We would like to thank D. Schlaffmann and R. Fris with the California Landscape Conservation Cooperative for hosting the panel, as well as for the development and coordination by D. Brewer and M. Haynes at the U.S. Fish and Wildlife Service National Conservation Training Center and S. Converse at the U.S. Geological Survey Patuxent Wildlife Research Center. C. Wilcox (California Department of Fish and Wildlife) and A. Hutzel (State Coastal Conservancy) offered their support for participation of their experts and attended presentations of the preliminary prototype results. G. Ballard provided helpful comments on an earlier draft. Any use of trade, product, or firm names in this publication is for descriptive purposes only and does not imply endorsement by the U.S. government.

\section{LITERATURE CITED}

Archibold, O. W. 1995. Coastal and marine ecosystems. Pages 388-424 in Ecology of world vegetation. First edition. Springer Netherlands, London, UK. http://dx.doi.org/10.1007/978-94-011-0009-0 12

Arkema, K. K., S. C. Abramson, and B. M. Dewsbury. 2006. Marine ecosystem-based management: from characterization to implementation. Frontiers in Ecology and the Environment 4 (10):525-532. http://dx.doi.org/10.1890/1540-9295(2006)4[525: MEMFCT]2.0.CO;2

Atwater, B. F., S. G. Conard, J. N. Dowden, C. W. Hedel, R. L. MacDonald, and W. Savage. 1979. History, landforms, and vegetation of the estuary's tidal marshes. Pages 347-385 in T. J. Conomos, editor. Fifty-eighth annual meeting of the Pacific Division of the American Association for the Advancement of
Science. Pacific Division of the American Association for the Advancement of Science, San Francisco, California, USA.

Barbier, E. B., S. D. Hacker, C. Kennedy, E. W. Koch, A. C. Stier, and B. R. Silliman. 2011. The value of estuarine and coastal ecosystem services. Ecological Monographs 81(2):169-193. http:// dx.doi.org/10.1890/10-1510.1

Beever, E. A., B. J. Mattsson, M. J. Germino, M. P. van der Burg, J. B. Bradford, and M. W. Brunson. 2014. Successes and challenges of 11 broad-extent conservation programs, from formation to implementation. Conservation Biology 28(2):302-314. http://dx. doi.org/10.1111/cobi.12233

Bell, F. W. 1997. The economic valuation of saltwater marsh supporting marine recreational fishing in the southeastern United States. Ecological Economics 21(3):243-254. http://dx.doi. org/10.1016/S0921-8009(96)00105-X

Bell, S., L. Tyrväinen, T. Sievänen, U. Pröbstl, and M. Simpson. 2007. Outdoor recreation and nature tourism: a European perspective. Living Reviews in Landscape Research 1:1-46. http:// dx.doi.org/10.12942/1rlr-2007-2

Bengtsson, M., Y. Shen, and T. Oki. 2006. A SRES-based gridded global population dataset for 1990-2100. Population and Environment 28(2):113-131. http://dx.doi.org/10.1007/s11111-007-0035-8

Bernhardt, J. R., and H. M. Leslie. 2013. Resilience to climate change in coastal marine ecosystems. Annual Review of Marine Science 5:371-392. http://dx.doi.org/10.1146/annurevmarine-121211-172411

Blomquist, S. M., T. D. Johnson, D. R. Smith, G. P. Call, B. N. Miller, W. M. Thurman, J. E. McFadden, M. J. Parkin, and G. S. Boomer. 2010. Structured decision-making and rapid prototyping to plan a management response to an invasive species. Journal of Fish and Wildlife Management 1(1):19-32. http://dx. doi.org/10.3996/JFWM-025

Bulleri, F., and M. G. Chapman. 2010. The introduction of coastal infrastructure as a driver of change in marine environments. Journal of Applied Ecology 47(1):26-35. http://dx.doi. org/10.1111/j.1365-2664.2009.01751.x

Cayan, D., P. Bromirski, K. Hayhoe, M. Tyree, M. Dettinger, and R. Flick. 2006. Projecting future sea level. A white paper from the California Energy Commission's California Climate Change Center. Publication number CEC-500-2005-202-SF. California Energy Commission, California Environmental Protection Agency, Sacramento, California, USA.

Cayan, D., M. Tyree, M. Dettinger, H. Hidalgo, T. Das, E. Maurer, P. Bromirski, N. Graham and R. Flick. 2009. Climate change scenarios and sea level rise estimates for the California 2009 Climate Change Scenarios Assessment. California Climate Change Center publication\#CEC-500-2009-014-F. California Energy Commission, California Environmental Protection Agency, Sacramento, California, USA.

Conroy, M. J., and J. T. Peterson. 2013. Decision making in natural resource management: a structured, adaptive approach. John Wiley \& Sons, West Sussex, UK. http://dx.doi.org/10.1002/9781118506196

Convertino, M., and L. J. Valverde, Jr. 2013. Portfolio decision analysis framework for value-focused ecosystem management. PloS One 8(6):e65056. http://dx.doi.org/10.1371/journal.pone.0065056 
Costanza, R., R. D’Arge, R. de Groot, S. Farber, M. Grasso, B. Hannon, K. Limburg, S. Naeem, R. V. O’Neill, J. Paruelo, R. G. Raskin, P. Sutton, and M. van den Belt. 1997. The value of the world's ecosystem services and natural capital. Nature 387:253-260. http://dx.doi.org/10.1038/387253a0

Costanza, R., O. Pérez-Maqueo, M. L. Martinez, P. Sutton, S. J. Anderson, and K. Mulder. 2008. The value of coastal wetlands for hurricane protection. Ambio 37(4):241-248. http://dx.doi. org/10.1579/0044-7447(2008)37[241:TVOCWF]2.0.CO;2

Duarte, C. M., I. J. Losada, I. E. Hendriks, I. Mazarrasa, and N. Marbà. 2013. The role of coastal plant communities for climate change mitigation and adaptation. Nature Climate Change 3 (11):961-968. http://dx.doi.org/10.1038/nclimate1970

Findlay, S., and D. Fischer. 2013. Ecosystem attributes related to tidal wetland effects on water quality. Ecology 94(1):117-125. http://dx.doi.org/10.1890/12-0464.1

Fujita, R., J. Lynham, F. Michelli, P. G. Feinberg, L. Bourillon, A. Sâenz-Arroyo, and A. C. Markham. 2013. Ecomarkets for conservation and sustainable development in the coastal zone. Biological Reviews 88(2):273-286. http://dx.doi.org/10.1111/ j.1469-185X.2012.00251.X

Gedan, K. B., M. L. Kirwan, E. Wolanski, E. B. Barbier, and B. R. Silliman. 2011. The present and future role of coastal wetland vegetation in protecting shorelines: answering recent challenges to the paradigm. Climatic Change 106(1):7-29. http://dx.doi. org/10.1007/s10584-010-0003-7

Goals Project. 2000. Baylands ecosystem species and community profiles: life Histories and environmental requirements of key plants, fish and wildlife. Prepared by the San Francisco Bay Area Wetlands Ecosystem Goal Project. P. R. Olofson, editor. San Francisco Bay Regional Water Quality Control Board, Oakland, California, USA.

Greenberg, R. 2012. The ecology of estuarine wildlife. Pages 357-380 in J. W. Day, W. M. Kemp, A. Yáñez-Arancibia, and B. C. Crump, editors. Estuarine ecology. Second edition. John Wiley \& Sons, Hoboken, New Jersey, USA. http://dx.doi. org/10.1002/9781118412787.ch14

Gregory, R., L. Failing, M. Harstone, G. Long, T. McDaniels, and D. Ohlson. 2012. Structured decision making: a practical guide to environmental management choices. John Wiley \& Sons, West Sussex, UK. http://dx.doi.org/10.1002/9781444398557

Grinsted, A., J. C. Moore, and S. Jevrejeva. 2010. Reconstructing sea level from paleo and projected temperatures 200 to 2100 AD. Climate Dynamics 34(4):461-472. http://dx.doi.org/10.1007/ $\underline{\text { s00382-008-0507-2 }}$

Hammond, J. S., R. L. Keeney, and H. Raiffa. 1999. Smart choices: a practical guide to making better life decisions. Broadway Books, New York, New York, USA.

Heller, N. E., and E. S. Zavaleta. 2009. Biodiversity management in the face of climate change: a review of 22 years of recommendations. Biological Conservation 142(1):14-32. http:// dx.doi.org/10.1016/j.biocon.2008.10.006

Henrion, M., J. S. Breese, and E. J. Horvitz. 1991. Decision analysis and expert systems. AI Magazine 12(4):64-91.
Howard, R. A. 1988. Decision analysis: practice and promise. Management Science 34:679-695. http://dx.doi.org/10.1287/ mnsc. 34.6.679

Jevrejeva, S., J. C. Moore, and A. Grinsted. 2010. How will sea level respond to changes in natural and anthropogenic forcings by 2100? Geophysical Research Letters 37(7):L07703. http://dx. doi.org/10.1029/2010GL042947

Jevrejeva, S., J. C. Moore, and A. Grinsted. 2012. Sea level projections to AD2500 with a new generation of climate change scenarios. Global and Planetary Change 80-81:14-20. http://dx. doi.org/10.1016/j.gloplacha.2011.09.006

Kettle, N. P. 2012. Exposing compounding uncertainties in sea level rise assessments. Journal of Coastal Research 28(1):161-173. http://dx.doi.org/10.2112/JCOASTRES-D-10-00011.1

King, S. E., and J. N. Lester. 1995. The value of salt marsh as a sea defence. Marine Pollution Bulletin 30(3):180-189. http://dx. doi.org/10.1016/0025-326X(94)00173-7

Kirwan, M. L., and A. B. Murray. 2007. A coupled geomorphic and ecological model of tidal marsh evolution. Proceedings of the National Academy of Sciences of the United States of America 104(15):6118-6122. http://dx.doi.org/10.1073/pnas.0700958104

Kirwan, M. L., and A. B. Murray. 2008. Ecological and morphological response of brackish tidal marshland to the next century of sea level rise: Westham Island, British Columbia, Canada. Global and Planetary Change 60(3-4):471-486. http://dx. doi.org/10.1016/j.gloplacha.2007.05.005

Knowles, N. 2010. Potential inundation due to rising sea levels in the San Francisco Bay region. San Francisco Estuary and Watershed Science 8(1):1-19. [online] URL: http://escholarship. org/uc/item/8ck5h3qn

Kuhnert, P. M., T. G. Martin, and S. P. Griffiths. 2010. A guide to eliciting and using expert knowledge in Bayesian ecological models. Ecology Letters 13(7):900-914. http://dx.doi.org/10.1111/ j.1461-0248.2010.01477.x

Levin, P. S., M. J. Fogarty, S. A. Murawski, and D. Fluharty. 2009. Integrated ecosystem assessments: developing the scientific basis for ecosystem-based management of the ocean. PLoS Biology 7 (1): e14. http://dx.doi.org/10.1371/journal.pbio.1000014

Linkov, I., and E. Moberg. 2011. Multi-criteria decision analysis: environmental applications and case studies. CRC, Boca Raton, Florida, USA.

Lougheed, V. L., B. Crosbie, and P. Chow-Fraser. 2001. Primary determinants of macrophyte community structure in 62 marshes across the Great Lakes basin: latitude, land use, and water quality effects. Canadian Journal of Fisheries and Aquatic Sciences 58 (8):1603-1612. http://dx.doi.org/10.1139/cjfas-58-8-1603

McCarthy, D. P., P. F. Donald, J. P. W. Scharlemann, G. M. Buchanan, A. Balmford, J. M. H. Green, L. A. Bennun, N. D. Burgess, L. D. C. Fishpool, S. T. Garnett, D. L. Leonard, R. F. Maloney, P. Morling, H. M. Schaefer, A. Symes, D. A. Wiedenfeld, and S. H. M. Butchart. 2012. Financial costs of meeting global biodiversity conservation targets: current spending and unmet needs. Science 338(6109):946-949. http://dx. doi.org/10.1126/science.1229803 
McGranahan, G., D. Balk, and B. Anderson. 2007. The rising tide: assessing the risks of climate change and human settlements in low elevation coastal zones. Environment and Urbanization 19 (1):17-37. http://dx.doi.org/10.1177/0956247807076960

Mitsch, W. J., and J. G. Gosselink. 1993. Wetlands. Second edition. Van Nostrand Reinhold, New York, New York, USA.

Mousavi, M., J. L. Irish, A. E. Frey, F. Olivera, and B. L. Edge. 2011. Global warming and hurricanes: the potential impact of hurricane intensification and sea level rise on coastal flooding. Climatic Change 104(3-4):575-597. http://dx.doi.org/10.1007/ s10584-009-9790-0

National Research Council (NRC). 2012. Sea-level rise for the coasts of California, Oregon, and Washington: past, present, and future. The National Academies Press, Washington, D.C., USA.

Needles, L. A., S. E. Lester, R. Ambrose, A. Andren, M. Beyeler, M. S. Connor, J. E. Eckman, B. A. Costa-Pierce, S. D. Gaines, K. D. Lafferty, H. S. Lenihan, J. Parrish, M. S. Peterson, A. E. Scaroni, J. S. Weis, and D. E. Wendt. 2013. Managing bay and estuarine ecosystems for multiple services. Estuaries and Coasts. http://dx.doi.org/10.1007/s12237-013-9602-7

Nicholls, R. J. 2004. Coastal flooding and wetland loss in the 21st century: changes under the SRES climate and socio-economic scenarios. Global Environmental Change 14(1):69-86. http://dx. doi.org/10.1016/j.gloenvcha.2003.10.007

Nichols, F. H., J. E. Cloern, S. N. Luoma, and D. H. Peterson. 1986. The modification of an estuary. Science 231:567-573. http:// dx.doi.org/10.1126/science.231.4738.567

Nichols, J. D., M. D. Koneff, P. J. Heglund, M. G. Knutson, M. E. Seamans, J. E. Lyons, J. M. Morton, M. T. Jones, G. S. Boomer, and B. K. Williams. 2011. Climate change, uncertainty, and natural resource management. Journal of Wildlife Management 75(1):6-18. http://dx.doi.org/10.1002/jwmg. 33

Runge, M. C., J. F. Cochrane, S. J. Converse, J. A. Szymanski, D. R. Smith, J. E. Lyons, M. J. Eaton, A. Matz, P. Barrett, J. D. Nichols, and M. J. Parkin. 2011a. An overview of structured decision making. Revised edition. U.S. Fish and Wildlife Service, National Conservation Training Center, Shepherdstown, West Virginia, USA.

Runge, M. C., S. J. Converse, and J. E. Lyons. 2011b. Which uncertainty? Using expert elicitation and expected value of information to design an adaptive program. Biological Conservation 144(4):1214-1223. http://dx.doi.org/10.1016/j. biocon.2010.12.020

Schrage, M. 2013. Serious play: how the world's best companies simulate to innovate. Harvard Business Press, Boston, Massachusetts, USA.

Small, C., and R. J. Nicholls. 2003. A Global analysis of human settlement in coastal zones. Journal of Coastal Research 19 (3):584-599.

Solomon, S., G.-K. Plattner, R. Knutti, and P. Friedlingstein. 2009. Irreversible climate change due to carbon dioxide emissions. Proceedings of the National Academy of Sciences of the United States of America 106(6):1704-1709. http://dx.doi.org/10.1073/ pnas. 0812721106
Starfield, A. M., and A. Jarre. 2011. Interdisciplinary modeling for an ecosystem approach to management in marine socialecological systems. Pages 105-119 in R. E. Ommer, R. I. Perry, K. Cochrane, and P. Cury, editors. World fisheries: a social-ecological analysis. Blackwell, Oxford, UK. http://dx.doi.org/10.1002/9781444392241. $\underline{\text { ch6 }}$

Stein, B. A., P. Glick, N. Edelson, and A. Staudt, editors. 2014. Climate-smart conservation: putting adaptation principles into practice. National Wildlife Federation, Washington, D.C., USA.

Stralberg, D., M. Brennan, J. C. Callaway, J. K. Wood, L. M. Schile, D. Jongsomjit, M. Kelly, V. T. Parker, and S. Crooks. 2011. Evaluating tidal marsh sustainability in the face of sea-level rise: a hybrid modeling approach applied to San Francisco Bay. PLoS One 6(11):e27388. http://dx.doi.org/10.1371/journal.pone.0027388

Takekawa, J. Y., I. Woo, H. Spautz, N. Nur, K. Grenier, J. L. MalamudRoam, J. C. Nordby, A. N. Cohen, F. Malamud-Roam, and S. E. Wainwright-De La Cruz. 2006. Environmental threats to tidal marsh vertebrates in the San Francisco Bay estuary. Studies in Avian Biology 32:176-197.

Thorne, K., K. Buffington, K. Swanson, and J. Takekawa. 2013. Storm episodes and climate change implications for tidal marshes in the San Francisco Bay estuary, California, USA. International Journal of Climate Change: Impacts and Responses 4(4):169-190.

Thorne, K. M., J. Y. Takekawa, and D. L. Elliott-Fisk. 2012. Ecological effects of climate change on salt marsh wildlife: a case study from a highly urbanized estuary. Journal of Coastal Research 285(6):1477-1487. http://dx.doi.org/10.2112/JCOASTRESD-11-00136.1

U.S. Fish and Wildlife Service (USFWS). 2013. Recovery plan for tidal marsh ecosystems of Northern and Central California. USFWS, Sacramento, California, USA. [online] URL: http:// www.fws.gov/sacramento/es/Recovery-Planning/Tidal-Marsh/ Documents/20131210 TMRP Vol1.pdf

U.S. Fish and Wildlife Service (USFWS). 2014. Structured decision making (SDM). National Conservation Training Center, Shepherdstown, West Virginia, USA. [online] URL: http://nctc. fws.gov/courses/programs/decision-analysis/structured-decisionmaking-overview.html

Veloz, S. D., N. Nur, L. Salas, D. Johgsomjit, J. Wood, D. Stralberg, and G. Ballard. 2013. Modeling climate change impacts on tidal marsh birds: restoration and conservation planning in the face of uncertainty. Ecosphere 4(4):art49. http://dx.doi. org/10.1890/ES12-00341.1

Vermeer, M., and S. Rahmstorf. 2009. Global sea level linked to global temperature. Proceedings of the National Academy of Sciences of the United States of America 106(51):21527-21532. http://dx.doi.org/10.1073/pnas.0907765106

Von Winterfeldt, D., and W. Edwards. 1986. Decision analysis and behavioral research. Cambridge University Press, Cambridge, UK.

Walker, B., S. Carpenter, J. Anderies, N. Abel, G. S. Cumming, M. Janssen, L. Lebel, J. Norberg, G. D. Peterson, and R. Pritchard. 2002. Resilience management in social-ecological 
systems: a working hypothesis for a participatory approach. Conservation Ecology 6(1): 14. [online] URL: http://www. consecol.org/vol6/iss1/art14

Walker, B., C. S. Holling, S. R. Carpenter, and A. Kinzig. 2004. Resilience, adabptability and transformability in social-ecological systems. Ecology and Society 9(2): 5. [online] URL: http://www. ecologyandsociety.org/vol9/iss $2 /$ art5

Wilson, K. A., E. C. Underwood, S. A. Morrison, K. R. Klausmeyer, W. W. Murdoch, B. Reyers, G. Wardell-Johnson, P. A. Marquet, P. W. Rundel, M. F. McBride, R. L. Pressey, M. Bode, J. M. Hoekstra, S. Andelman, M. Looker, C. Rondinini, P. Kareiva, M. R. Shaw, and H. P. Possingham. 2007. Conserving biodiversity efficiently: what to do, where, and when. PLoS Biology 5(9): e223. http://dx.doi.org/10.1371/journal.pbio.0050223

Zimmerman, R. J., T. J. Minello, and L. P. Rozas. 2002. Salt marsh linkages to productivity of Penaeid shrimps and blue crabs in the Northern Gulf of Mexico. Pages 293-314 in M. P. Weinstein and D. A. Kreeger, editors. Concepts and controversies in tidal marsh ecology. Springer, Dordrecht, The Netherlands. http://dx.doi. org/10.1007/0-306-47534-0 14 
Appendix 1. Supplementary information regarding a structured decision making (SDM) process to inform management of tidal marshes in San Francisco Bay (SFB), California USA.

\section{METHODS}

\section{Study Area}

A tremendous amount of information is available on the internet about the San Francisco Bay estuary including tidal marshes. For detailed maps and information about SFB (see http://www.sfei.org/content/ecoatlas_habitats, EcoAtlas of Baylands).

\section{Problem framing:}

Guidelines for workshop were to: (1) limit the number of expert panelists to 10-15; (2) require them to attend the entire 5-day session; and (3) preferentially invite resource managers, planners, and policy makers over scientists to focus more on defining the management questions and objectives.

We then developed a series of questions related to our problem statement:

- When and where should restoration or adaptation occur?

- How do we evaluate cost-effectiveness of actions?

- Is there a way to maximize or optimize benefits?

- What are the considerations of time and spatial scales for this problem?

- How do we compare the cost of restoration with the wetland benefits and services gained over the short- and long-term?

- Should we focus on preserving existing marshes or on creating or re-establishing them?

- Should there be a focus on particular target species?

\section{RESULTS}

\section{Consequences}

With the exception of human benefits that were only evaluated for 2020, the fundamental objectives were evaluated at both the 2020 and 2050 time horizons. In addition to simplifying the decision model, focusing solely on the shorter-term horizon for human benefits is consistent with the limited timeframe for projections of human health due to coastal hazards under climate change. 
We assigned a measureable attribute to each objective along with external factors so that consequences of alternative management strategies could be evaluated (Table A1.1, Main Document Table 2). For likelihood of recovering endangered species, we chose as an example the California Ridgeway's Rail (henceforth Clapper Rail; Rallus obsoletus obsoletus), a federally endangered and secretive marsh bird that is representative of species requiring mid to high-elevation tidal marsh. For recovery of the Clapper Rail, we used the likelihood of meeting its habitat requirements defined in the tidal marsh recovery plan (USFWS 2009).

To incorporate important tidal marsh ecosystem services in the decision analytic framework we developed two multi-attribute indices (Main Document Table 2). First, an index of marsh ecosystem integrity was based on five attributes including the area of marsh within three elevation classes (i.e., low, mid, and high), native plant species richness, and accretion rate. Our marsh ecosystem index ( 0 to 5 ) was the sum of scores for the five individual ecosystem attributes; each ecosystem attribute received a score of 0 to 1 where 1 was the most desired outcome. The marsh ecosystem index was developed to be independent of Clapper Rail habitat requirements. Second, an index of human benefits incorporated three attributes including the incidence of mosquito-borne diseases, condition of human infrastructure with respect to flooding, and recreational opportunities in tidal marshes. As with the marsh integrity index, each attribute of the human benefits index received a score of 0 to 1 for least to most desirable and was then summed for a total human-benefit score of 0 to 3 . When modeling outcomes resulting from the alternative management strategies with respect to the fundamental objectives at each time horizon, we accounted for uncertainty regarding the available budget and the annual frequency of intense storms (Table A1.2).

Our BDN was comprised of 10 nodes, including a utility node, a decision node, and 8 stochastic nodes (Main Document Figure 4; Table 2). The Netica file containing the BDN can be accessed in Appendix 2. Of the stochastic nodes, one represented external storms and two represented operating budgets under two time frames (i.e., 2012-2020 and 2020-2050). SLR was treated as a constant linear increase in this prototype due to the shorter time horizon and because SLR is expected to have a gradual increase through 2050. Five of the other stochastic nodes represented fundamental objectives regarding Clapper Rail recovery, marsh ecosystem integrity, and human benefits. The remaining stochastic node was the budget from 2021-2050, which represented the only means objective in the network. Predictor variables were represented by arrows going into each stochastic node within the BDN (Main Document Figure 5). To our knowledge, there were no mathematical predictive models available to parameterize the probabilistic relationships in our BDN. For the purposes of rapid prototyping and in minimizing the 
required predictions to elicit from the panel, we discretized the continuous stochastic nodes for the analysis into two categories each (Main Document Table 4).

For a baseline parameterization of our BDN, we elicited expert judgments from stakeholders and scientists on the panel for quantifying the likelihood of optimistic and pessimistic scenarios for external influences along with the likelihood of possible outcomes for the objectives. These likelihoods were entered in probabilistic contingency tables for each of the 8 stochastic nodes. For the external factors, the contingency table had just one probability for each of the two possible levels representing belief weights that sum to 100 and represent alternate hypotheses about the magnitude of these factors. The objectives, however, required specification of a larger set of probabilities for their predicted outcomes. For example, there were $2 \times 2 \times 2 \times 5=40$ possible combinations of predictor states for the 2050 marsh ecosystem index, which was a function of the 2020 marsh ecosystem index, 2021-2050 budget, frequency of storms, and the allocation strategy, respectively. For each of the possible predictor states regarding the 2050 marsh ecosystem index, each expert was asked to assign a probability that the marsh ecosystem index would be 0-3 as opposed to 4-5.

Consistent with the Delphi method stakeholders and scientists on the panel provided independent predictions for stochastic nodes representing fundamental objectives with the exception of human benefits at 2020, which were elicited by consensus across the panel for the sake of rapid prototyping. Likewise, predicted likelihoods for levels of storms and budgets were elicited as a group. For probabilities that were elicited individually, we evaluated the logical consistency of the original elicited predictions from each panel member. For example if probability of Clapper Rail recovery was 0.9 when assuming low frequency of intense storms, then probability of rail recovery under high frequency of intense storms must be $\leq 0.9$ because of the potential negative (but not positive) impacts of storm events on rail habitat. Whenever such logic was violated, we corrected the probabilities to ensure logical consistency. Elicitation fatigue is an important source of bias when experts are asked to provide many predictions in a short period of time.

Summary statistics of individually elicited and corrected predictions were provided to the expert panel. Panel members were then offered the opportunity to revise their predictions in light of these, but in our case, none of them did so. In addition to incorporating elicited predictions as a baseline parameterization, the BDN allowed for sensitivity analyses to examine the relative importance of alternate sources of uncertainty about management effectiveness and environmental dynamics (see Sensitivity analyses).

\section{Tradeoffs and optimization}


An important element of our decision analysis was accounting for tradeoffs among multiple fundamental objectives. To quantify these tradeoffs, we asked the panel of decision-makers and stakeholders to independently express a utility value representing their relative preference for each of the $2^{5}=32$ possible outcomes across the five measures for the fundamental objectives (Table A1.2). Fundamental objectives were represented in our BDN by stochastic nodes with arrows connecting to the utility node (Main Document Figure 4). Utility values were elicited on a scale from 0 to 100 , where 0 represented the least favorable and 100 the most favorable outcome. Taken as an example, we asked each team member to assign a utility value to the possible outcome where marsh integrity is low in 2020 but high in 2050, California clapper rail is not recovered in 2020 nor 2050, and human benefits are low in 2020. Panelists filled out their utility value then for every possible outcome with respect to the five fundamental objectives.

Again consistent with the Delphi method, stakeholders on the panel were asked to independently assign their utility values to alternative outcomes in terms of the fundamental objectives. Likewise, we offered stakeholders the opportunity to revise their utilities following a group discussion, but none did. To arrive at a consensus utility value for each possible outcome, we presented participants with summary statistics on each set of elicited utility values across team members. As with the predictions (see

Consequences, above), panelists were offered to modify their elicited utility value following a group discussion, but they were satisfied with the original values and declined. As with the predicted probabilities, we evaluated the logical consistency of the original elicited utilities from each stakeholder. For example if a stakeholder assigned a utility of 10 to a case where all outcomes were pessimistic except for human benefits, then all cases with an optimistic outcome for human benefits should receive a utility of $\geq 10$. Whenever such logic was violated, we corrected the utilities to ensure logical consistency. The panelists agreed to use the average of the final elicited utilities across all experts to reflect the utility of a given potential outcome, giving equal weight of importance to each expert. We used the upper and lower $95 \%$ confidence intervals among elicited utilities for computing the corresponding upper and lower $95 \%$ confidence intervals for expected utilities among alternative allocations to account for the variation in utilities among experts.

We used Netica to compute the expected utility for each of the allocation strategies based on the elicited likelihoods of external effects and predicted outcomes along with the elicited utility values. The expected utility from an allocation was the value a decision maker would expect to realize following implementation of that allocation and was on the same unit scale as the elicited utilities, which ranged 0-100. The maximum expected utility across alternative allocations then indicated the optimal decision. 


\section{Sensitivity analyses}

We conducted two sets of one-way sensitivity analyses where we adjusted one factor at a time within the BDN to investigate its effect on decision-making. First, we evaluated how expected utilities, and therefore how the optimal decision, changed under alternative assumptions representing knowledge about the system. For this purpose we toggled predictions one at a time between their low and high values for each of the stochastic nodes representing external factors and objectives. After each perturbation, expected utilities were recalculated. For example for the Clapper Rail perturbation, we computed the expected utilities when Clapper Rails were assumed to be recovered by 2020 and computed the expected utilities again assuming rails were unrecovered by 2020 while all other stochastic nodes retained their baseline parameterization. Across the 8 stochastic nodes, we conducted 16 perturbations. If the strategy that was optimal under the baseline parameterization still had the maximum expected utility following perturbations of a particular node, then we concluded the decision was robust to that source of uncertainty. Otherwise, we concluded the decision was sensitive to that stochastic node.

Second, we examined how expected utilities changed under alternative scenarios regarding the utility values placed on potential outcomes. To this end we constructed alternative scenarios representing three types of advocacy, with each advocacy scenario corresponding to one of three focal fundamental objectives. The advocacy scenarios were developed to illustrate the potential for a stakeholder campaign to advocate a preference for a particular objective and how this would change the optimal decision, if at all. For example, Clapper Rail Advocacy was constructed to illustrate the consequences of hypothetically enhancing stakeholder preference for long-term Clapper Rail recovery over the other objectives. To represent this scenario, we selected the maximum utility across participants for each possible outcome where the Clapper Rail is recovered by 2050 and the minimum utility for outcomes when rails were unrecovered. This set of modified utilities was then entered into the utility node of the BDN, and expected utilities were recomputed. Scenarios for Marsh Advocacy and Human Benefits Advocacy were constructed in an analogous fashion representing advocacy for long-term marsh integrity and short-term human benefit. These three scenarios provided a contrast to the Status Quo Advocacy, which was represented by the average utility across participants for each potential outcome under the baseline parameterization (Figure A1.1, A1.2).

The optimal allocation was robust when perturbing stochastic nodes or adjusting advocacy scenarios individually (Figures A1.1 and A1.2). Exceptions occurred when conducting a two-way sensitivity analysis by simultaneously assuming the Marsh Advocacy scenario and optimistic scenarios for storms or for marsh integrity at 2020, 
which resulted in the Marsh Migration allocation strategy becoming the optimal decision (not shown in Figure A1.1). Resolving the uncertainty about storm frequency or marsh integrity at 2020 under the Marsh Advocacy scenario would be expected to increase expected utility by an EVPI $<0.4$ on a scale of 0 to 100 . This quantity is the Expected Value of Perfect Information (EVPI), which is the value of resolving a particular source of uncertainty. In cases where perturbations did not change the optimal decision, EVPI equaled zero.

\section{Spatiotemporal linkages}

Conservation of coastal ecosystems is complicated not only by socioecological complexity, but also by having decisions that are enacted among numerous spatial units and whose consequences are linked across space and time (Wilson et al. 2011). Our framework was intended as an initial prototype and a case study that considered the entire SFB estuary as a single management unit and temporal allocation options that were prescriptive rather than adaptive. Scaling up the effects of conservation strategies from individual management units to regional scales is a great challenge on its own (Mattsson et al. 2012). Recognizing that biophysical processes and management constraints vary at intermediate subregional scales within SFB (Goals Project 1999), this subregional level may provide a critical lynchpin for linking the local management strategies to regionalscale outcomes. This challenge of linked spatial scales combined with the challenge of developing a matrix of optimal strategies across space and time poses a difficult problem, but one that can be solved with the tools and methods available in the literature and in the SDM toolbox (Conroy and Peterson 2012, Runge et al. 2011, Wilson et al. 2011). A starting point may be to identify optimal strategies to allocate climate restoration actions across space and time through 2050, as the Climate-Smart Restoration strategy was optimal under our aspatial decision analytic framework (Runge et al. 2011, Wilson et al. 2011, Conroy and Peterson 2012,). A more robust and transparent strategy would explicitly account for these spatiotemporal linkages in the consequences of decisions for conserving the resilience of the SFB ecosystem and the services it provides.

Table A1.1. Draft objectives that were later refined and condensed for the prototype decision model.

Draft objectives

Increase understanding of climate change forcing on wetland processest Increase understanding of where and how wetlands will migrate and persist: 
Provide transition areas to allow for wetlands to migrate upslope with SLR

Maintain and expand tidal wetlands functions and services in light of future climate change Increase wetland resiliency against extreme climatic events

Manage tidal wetlands to maximize biodiversity, diversity of wetland types

Recovery of endangered species

Ensure habitat persistence and quality for endangered species

Reduce non-climate stressors to increase resiliency (subset of wetland functions and services)

Maintain human services

Clearly articulate a justification for wetlands protection, management and restoration $\dagger$

Be open to innovate ideas for restoration and augmentation of wetlands $\uparrow$

Develop engineering methods to sustain marsh plain, such as dredge or upland sediment use Understand tradeoffs of linked consequences of mud flat, marsh and upland transition $\neq$

$\dagger$ Process objective - a goal to improve the planning process for reaching decisions

$\neq$ Knowledge objective - a goal describing the need for information to support making decisions

Table A1.2. Utility values elicited from stakeholder panel.

Averages presented as mean \pm standard deviation.

\begin{tabular}{ccccc}
\hline \multicolumn{5}{c}{ Outcome scenarios† } \\
\hline Marsh & Marsh & Rail & Rail & Human \\
Integrity & Integrity & recovery & recovery & benefits \\
in 2020 & in 2050 & by 2020 & by 2050 & in 2020 \\
\hline low & low & no & no & low \\
low & HIGH & no & no & low
\end{tabular}

\begin{tabular}{ccccccccccccc}
\hline \multicolumn{11}{c}{ Stakeholder utility values $\$$} \\
\hline 1 & 2 & 3 & 4 & 5 & 6 & 7 & 8 & 9 & Average \\
& & & & & & & & & & \\
\hline 0 & 0 & 0 & 0 & 0 & 0 & 0 & 0 & 0 & 0 & \pm & 0 \\
5 & 5 & 10 & 20 & 50 & 10 & 40 & 1 & 10 & 17 & \pm & 17
\end{tabular}




\begin{tabular}{|c|c|c|c|c|c|c|c|c|c|c|c|c|c|c|c|c|}
\hline low & low & YES & no & low & 10 & 5 & 5 & 20 & 18 & 5 & 20 & 20 & 5 & 12 & \pm & 7 \\
\hline low & HIGH & YES & no & low & 30 & 10 & 15 & 40 & 50 & 10 & 40 & 50 & 10 & 28 & \pm & 17 \\
\hline low & low & no & YES & low & 10 & 6 & 10 & 40 & 45 & 5 & 60 & 20 & 10 & 23 & \pm & 20 \\
\hline low & HIGH & no & YES & low & 30 & 10 & 35 & 50 & 85 & 15 & 70 & 40 & 15 & 39 & \pm & 26 \\
\hline low & low & YES & YES & low & 20 & 11 & 15 & 50 & 55 & 8 & 75 & 78 & 20 & 37 & \pm & 28 \\
\hline low & HIGH & YES & YES & low & 50 & 15 & 35 & 70 & 85 & 15 & 80 & 85 & 25 & 51 & \pm & 30 \\
\hline low & low & no & no & HIGH & 20 & 5 & 10 & 40 & 10 & 7 & 30 & 5 & 5 & 15 & \pm & 13 \\
\hline low & HIGH & no & no & HIGH & 60 & 25 & 45 & 40 & 60 & 13 & 60 & 37 & 10 & 39 & \pm & 20 \\
\hline low & low & YES & no & $\mathrm{HIGH}$ & 30 & 20 & 16 & 40 & 18 & 10 & 40 & 70 & 15 & 29 & \pm & 19 \\
\hline low & HIGH & YES & no & HIGH & 70 & 70 & 60 & 50 & 60 & 13 & 65 & 80 & 20 & 54 & \pm & 23 \\
\hline low & low & no & YES & $\mathrm{HIGH}$ & 40 & 35 & 25 & 50 & 50 & 7 & 68 & 40 & 15 & 37 & \pm & 19 \\
\hline low & HIGH & no & YES & HIGH & 70 & 70 & 70 & 70 & 85 & 15 & 85 & 70 & 20 & 62 & \pm & 26 \\
\hline low & low & YES & YES & $\mathrm{HIGH}$ & 40 & 50 & 30 & 50 & 55 & 10 & 75 & 80 & 30 & 47 & \pm & 22 \\
\hline low & HIGH & YES & YES & HIGH & 80 & 75 & 70 & 80 & 85 & 20 & 95 & 90 & 35 & 70 & \pm & 25 \\
\hline HIGH & low & no & no & low & 20 & 5 & 20 & 20 & 20 & 5 & 10 & 20 & 40 & 18 & \pm & 11 \\
\hline HIGH & HIGH & no & no & low & 40 & 10 & 55 & 50 & 65 & 18 & 50 & 37 & 50 & 42 & \pm & 18 \\
\hline $\mathrm{HIGH}$ & low & YES & no & low & 30 & 10 & 16 & 40 & 18 & 5 & 20 & 50 & 40 & 25 & \pm & 15 \\
\hline HIGH & HIGH & YES & no & low & 50 & 15 & 70 & 60 & 65 & 18 & 60 & 60 & 60 & 51 & \pm & 20 \\
\hline HIGH & low & no & YES & low & 30 & 10 & 20 & 50 & 45 & 5 & 65 & 50 & 45 & 36 & \pm & 20 \\
\hline HIGH & HIGH & no & YES & low & 50 & 15 & 60 & 60 & 90 & 25 & 75 & 80 & 70 & 58 & \pm & 25 \\
\hline HIGH & low & YES & YES & low & 40 & 11 & 50 & 50 & 60 & 8 & 75 & 78 & 50 & 47 & \pm & 25 \\
\hline HIGH & HIGH & YES & YES & low & 70 & 20 & 95 & 80 & 90 & 25 & 85 & 100 & 80 & 72 & \pm & 29 \\
\hline HIGH & low & no & no & $\mathrm{HIGH}$ & 60 & 10 & 16 & 50 & 10 & 7 & 45 & 20 & 40 & 29 & \pm & 20 \\
\hline $\mathrm{HIGH}$ & HIGH & no & no & $\mathrm{HIGH}$ & 90 & 55 & 65 & 70 & 65 & 35 & 65 & 37 & 60 & 60 & \pm & 17 \\
\hline HIGH & low & YES & no & $\mathrm{HIGH}$ & 60 & 45 & 16 & 50 & 18 & 10 & 55 & 70 & 50 & 42 & \pm & 22 \\
\hline HIGH & HIGH & YES & no & HIGH & 90 & 85 & 85 & 70 & 65 & 50 & 85 & 80 & 70 & 76 & \pm & 13 \\
\hline HIGH & low & no & YES & $\mathrm{HIGH}$ & 80 & 65 & 60 & 50 & 80 & 10 & 68 & 70 & 60 & 60 & \pm & 21 \\
\hline $\mathrm{HIGH}$ & HIGH & no & YES & HIGH & 90 & 95 & 95 & 80 & 100 & 75 & 95 & 80 & 70 & 87 & \pm & 11 \\
\hline $\mathrm{HIGH}$ & low & YES & YES & HIGH & 80 & 65 & 75 & 80 & 80 & 10 & 90 & 90 & 60 & 70 & \pm & 25 \\
\hline $\mathrm{HIGH}$ & HIGH & YES & YES & HIGH & 100 & 100 & 100 & 100 & 100 & 100 & 100 & 100 & 100 & 100 & \pm & 0 \\
\hline
\end{tabular}

$\dagger$ Outcomes presented as binary levels of five attributes of fundamental objectives including an index of marsh integrity, recovery of California clapper rail, and an index of human benefits from tidal marshes.

IUtility values for the worst-case and best-case scenarios were fixed at 0 and 100, respectively. Stakeholder identities are anonymized to protect their anonymity. One member recused themselves from the elicitation. 
Figure A1.1. Changes in expected utilities based on a one-way sensitivity analysis among four advocacy scenarios for conservation and restoration of tidal marshes in San Francisco Bay through 2050. Three advocacy scenarios (A-C) were represented by choosing one of nine elicited utility values among stakeholders for each outcome. For example, in the Clapper Rail Advocacy scenario (A), the maximum utility among experts was chosen for each outcome where the California clapper rail was recovered in 2050, otherwise the minimum utility was chosen. This method was used to select a set of perturbed utilities that were used to generate the expected utilities for alternative strategies under each advocacy scenario. In graph D, each bar height and whisker represents the mean and $95 \%$ confidence interval estimated from the distribution of elicited utilities among stakeholders. No whiskers are shown in the remaining graphs, as they each represent a single set of perturbed utility values. The Climate-Smart Restoration allocation strategy had the highest expected utility among the alternatives under all four advocacy scenarios.

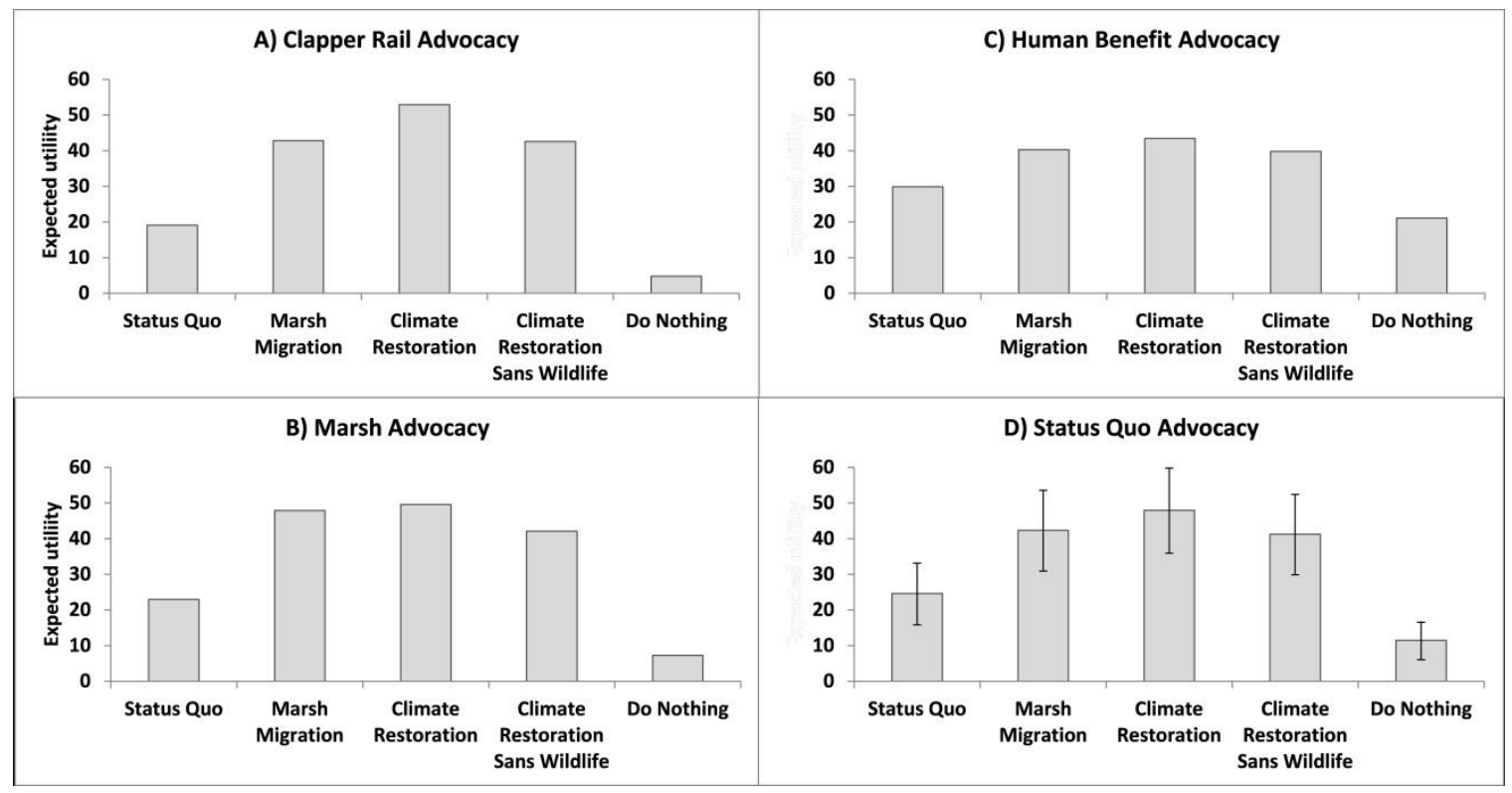


Figure A1.2. Changes in expected utilities based on a one-way sensitivity analysis among contrasting assumptions regarding predictions for stochastic nodes in a Bayesian decision network to inform conservation and restoration of tidal marshes in San Francisco Bay. Bar heights were based on a baseline parameterization of the stochastic nodes; the perturbed node is identified at the top of each graph. Upper dashed line and lower solid lines represent optimistic and pessimistic perturbations of the predictions, respectively.

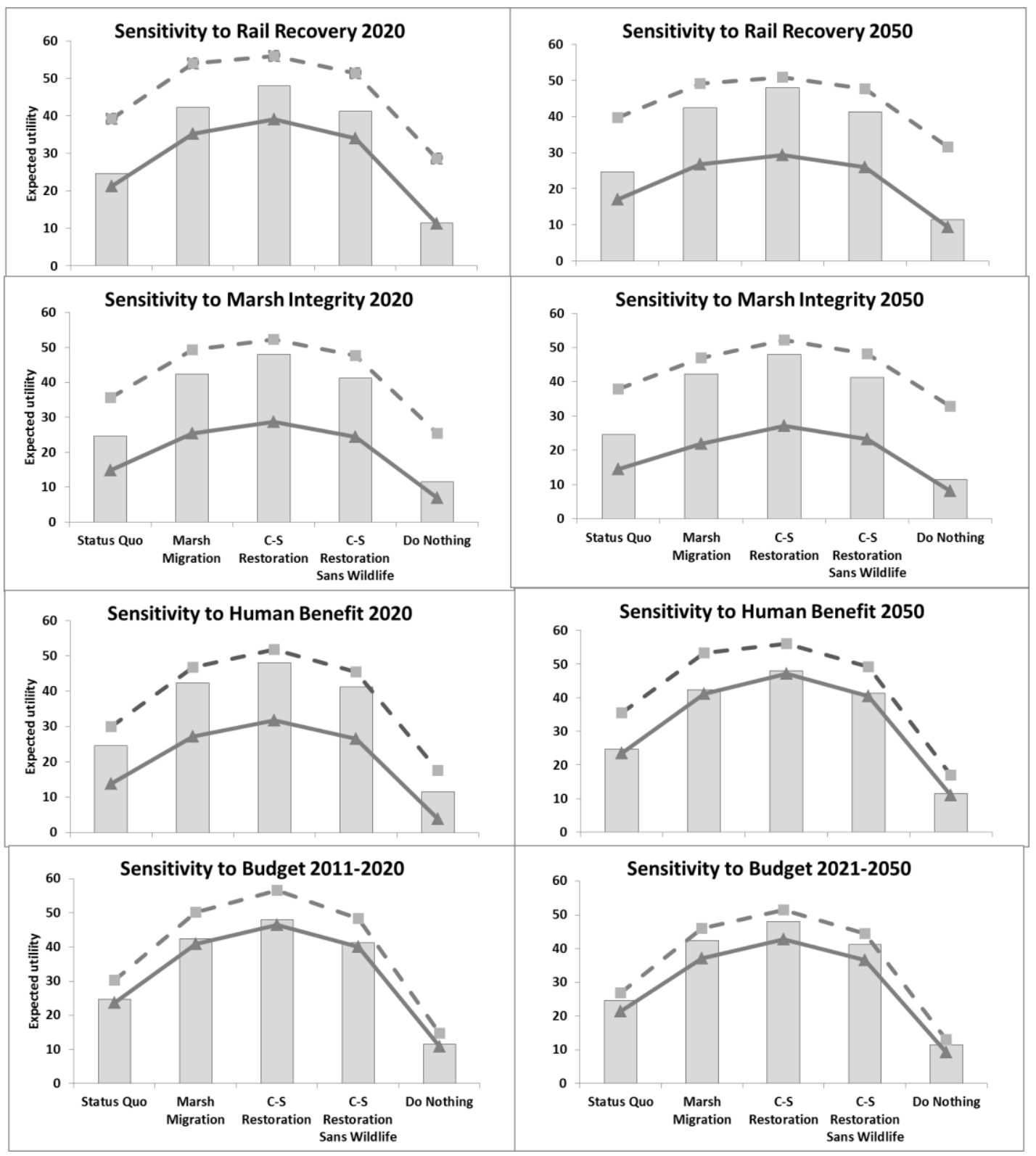


Appendix 2. File containing input for the Bayesian Decision Network (BDN). Download the free version of the Netica software (http://www.norsys.com/) to run and review the network.

Please click here to download file 'appendix2.neta'. 